RFP-4165

October 4, 1988

RFP-4165

October 4, 1988

TANK EVALUATION SYSTEM:

SHIELDED ANNULAR TANK APPLICATION

D. A. Freier

Rockwell International

\author{
Aerospace Operations \\ Rocky Flats Plant \\ P.O. Box 464 \\ Golden, Colorado 80402-0464
}

U. S. DEPARTMENT OF ENERGY CONTRACT DE-AC04-76DPO3533

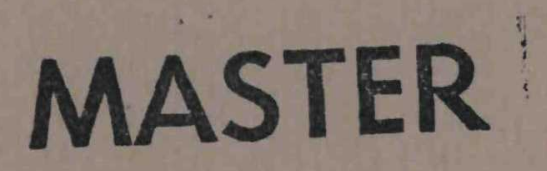




\section{DISCLAIMER}

"This report was prepared as an account of work sponsored by an agency of the United States Government. Neither the United States Government nor any agency thereof, nor any of their employees, makes any warranty, express or implied, or assumes any legal liability or responsibility for the accuracy, completeness, or usefulness of any information, apparatus, product, or process disclosed, or represents that its use would not infringe privately owned rights. Reference herein to any specific commercial product, process, or service by trade name, trademark, manufacturer, or otherwise, does not necessarily constitute or imply its endorsement, recommendation, or favoring by the United States Government or any agency thereof. The views and opinions of authors expressed herein do not necessarily state or reflect those of the United States Government or any agency thereof."

Printed in the United States of America

Available from the

National Technical Information Service

U.S. Department of Commerce

Springfield, Virginia 22161

Price Code: 001-025 pages, Code A02

Price Code: 026-050 pages, Code A03

Price Code: $051-075$ pages, Code A04

Price Code: 076-100 pages, Code A05

Price Code: 101-125 pages, Code A06

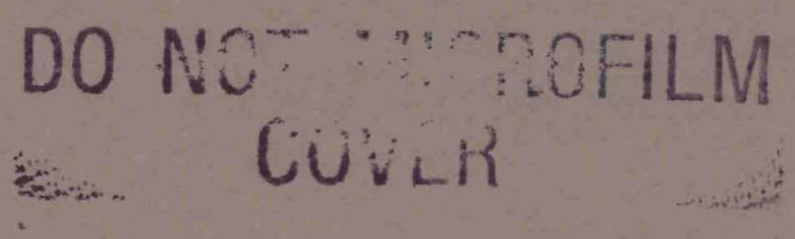




\section{DISCLAIMER}

This report was prepared as an account of work sponsored by an agency of the United States Government. Neither the United States Government nor any agency Thereof, nor any of their employees, makes any warranty, express or implied, or assumes any legal liability or responsibility for the accuracy, completeness, or usefulness of any information, apparatus, product, or process disclosed, or represents that its use would not infringe privately owned rights. Reference herein to any specific commercial product, process, or service by trade name, trademark, manufacturer, or otherwise does not necessarily constitute or imply its endorsement, recommendation, or favoring by the United States Government or any agency thereof. The views and opinions of authors expressed herein do not necessarily state or reflect those of the United States Government or any agency thereof. 


\section{DISCLAIMER}

Portions of this document may be illegible in electronic image products. Images are produced from the best available original document. 
Printed

October 4, 1988
RFP-4165

UC-38 ENGINEERING

AND EQUIPMENT

DOE/OSTI-4500 (Rev. 73 )

$\mathrm{RFP}-4165$

DE89 004430
TANK EVALUATION SYSTEM:

\section{SHIELDED ANNULAR TANK APPLICATION}

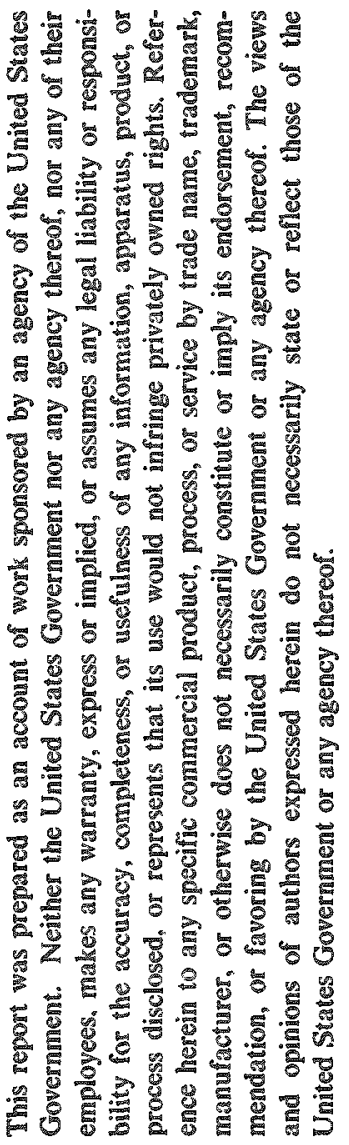

D. A. Freier

R. L. Thomas, Editor

L. M. Morales, Compositor
ROCKWELL INTERNATIONAL
SUBJECT DESCRIPTORS

Neutron Transmission Shielded Annular Tank Shielding Verification

Prepared under Contract DE-AC04-76DP03533

for the

$$
\begin{gathered}
\text { AEROSPACE OPERATIONS } \\
\text { ROCKY FLATS PLANT } \\
\text { P. O. BOX } 464
\end{gathered}
$$

GOLDEN, COLORADO 80402-0464

U.S. Department of Eneriy 
RFP-4165 


\section{CONTENTS}

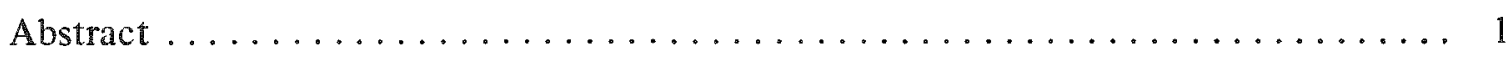

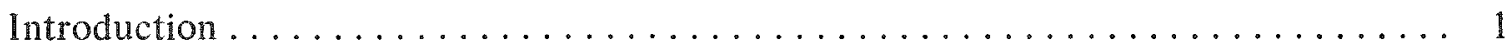

General . . . . . . . . . . . . . . . . . . . . 1

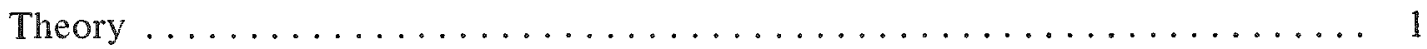

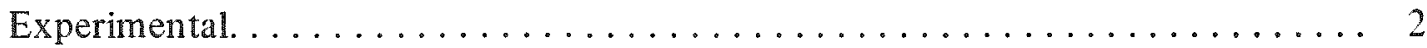

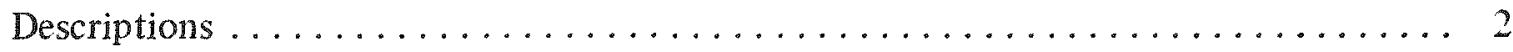

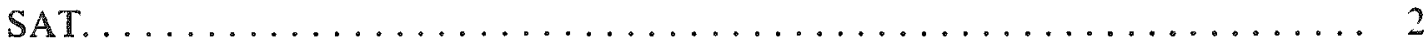

TEST Automated Scanner. ........................... 3

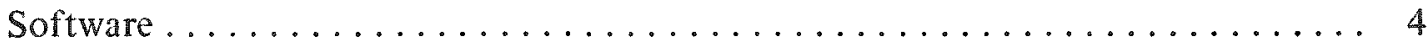

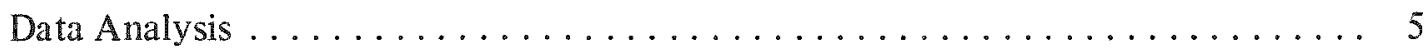

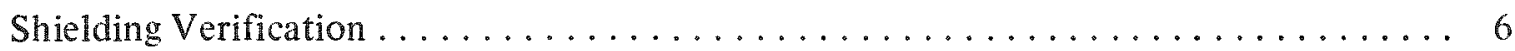

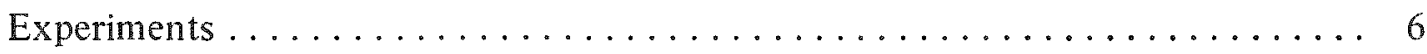

Results ........................ 7

Resolution Studies $\ldots \ldots \ldots \ldots \ldots \ldots \ldots \ldots \ldots \ldots \ldots \ldots \ldots \ldots \ldots \ldots$

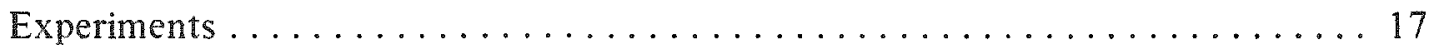

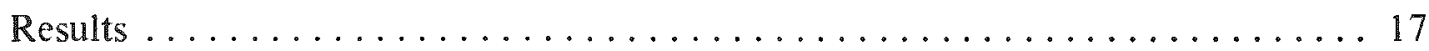

Source-Simulated Holdup . . . . . . . . . . . . . . . . . . . . . . . . . . 19

Experiments ......................... 19

Results ................................. 19

Production Application. ........................... 24

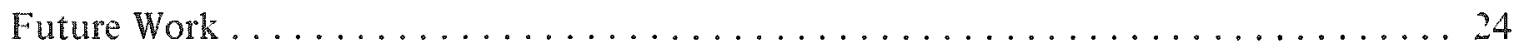

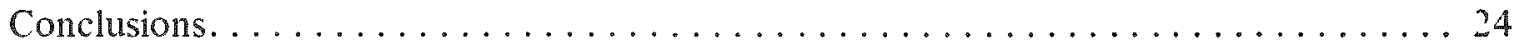

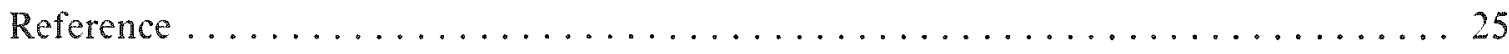

Appendix A. Rad-Stop Specifications . . . . . . . . . . . . . . . . 27

Appendix B. TEST Equipment. ........................ 28

Appendix C. Sample SATERR Program Output. . . . . . . . . . . . . . . . 29

Appendix D. Statistical Data Analysis . . . . . . . . . . . . . . . . 30 
RFP-4165 


\section{A CKNOWLED GMENTS}

I would like to thank Robert Miles and Richard Santopietro. whose support kept the TEST scanner operating throughout the experimentation process. Thanks to John Fleissner, whose help in reducing and analyzing the data was invaluable. I am grateful to craftsmen Bill Peterson and Virgil Peterson for changing the Shielding configurations. work they performed promptly and cheerfully, I would also like to express my appreciation to Blaise Mo for his support for the project and the Critical Mass Laboratory for allowing me use of their laboratory for TEST experimentation. 
RFP-4165

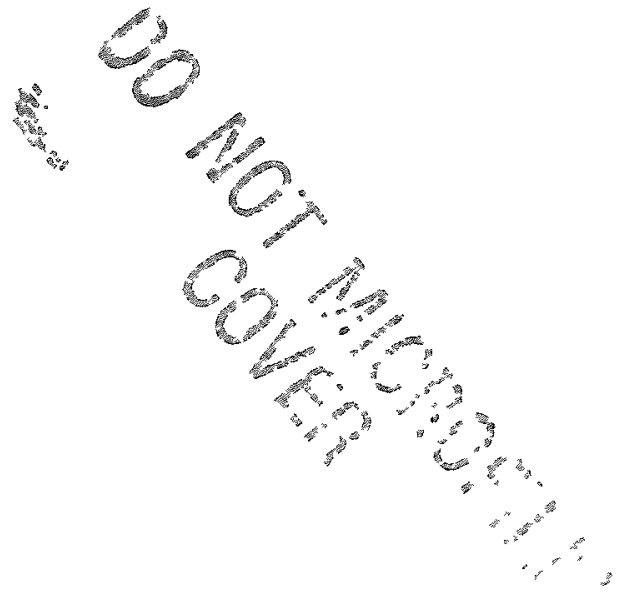




\title{
TANK EVALUATION SYSTEM: SHIELDED ANNULAR TANK APPLICATION
}

\author{
D. A. Freier
}

\section{ABSTRACT}

TEST (Tank Evaluation SysTem) is a research project utilizing neutron interrogation techniques to analyze the content of nuclear poisons and moderators in tank shielding. TEST experiments were performed on an experimental SAT (Shielded Annular Tank) at the Rocky Flats Plant. The purpose of these experiments was threefold: (1) to assess TEST application to SATs, (2) to determine if Nuclear Safety inspection criteria could be met, and (3) to perform a preliminary calibration of TEST for SATs.

Several experiments were performed, including measurements of 11 tank shielding configurations, source-simulated holdup experiments, analysis of three detector modes, resolution studies, and TEST scanner geometry experiments.

These experiments indicate that TEST could be used for shielding verification to determine whether one layer ( 3 in.) of polyethylene or one ring ( $1 / 4 \mathrm{in.}$ ) of Rad-Stop is missing from the tank shielding. Holdup experiments indicate the feasibility of using TEST for Nuclear Safety determination of plutonium holdup in the tank at the proposed limit of $2500 \mathrm{~g}$ of plutonium: additional development is necessary, however, before releasing TEST for holdup estimation of production tanks. Resolution studies and scanner geometry experiments indicated that TEST scans should be performed with the source located in the center void of the tank for increased detector sensitivity. Results from the detector mode experiments indicated that the collimated detector mode should be used.

Future work involves development of a continuous background measurement system as well as development of shield and holdup standards. Both issues are currently being addressed.

\section{INTRODUCTION}

\section{General}

The shielded annular tank (SAT) is being developed at the Rocky Flats Plant for the safe storage of intermediate volumes of fissile solutions. An in-situ method is required to verify the presence of the shielding on SATs. This verification will be performed prior to acceptance of each SAT and at a frequency determined by Criticality Engineering. A SAT would fail the shiclding inspection if the equivalent of one ring of Rad-Stop. or $20 \%$ of the polyethylene. was missing in any region of the tank. In addition. a method is needed to determine whether plutonium holdup in the tank is greater than the proposed Nuclear Safety limit of $2500 \mathrm{~g}$ of plutonium.

\section{Theory}

TEST (Tank Evaluation SysTem) is a proposed method for the shielding verification and plutonium holdup measurements. TEST, conceived by G. R. Goebel (now with EG\&G), uses neutron transmission and absorption data to verify the presence of neutron poisons and moderators, i.e., boron and hydrogen, in the tank shielding. TEST utilizes a californium-252 source positioned diametrically opposed to a bank of helium-3 neutron detectors as an interrogation system. The entire $360^{\circ}$ for the full vertical height of the tank is then scanned. The neutron count rate increases while scanning through an area from which shielding is missing. The neutron count rate also increases when plutonium holdup is present in the tank. By performing two scans, one without the source (holdup scan) and one with the source (boron sean), plutonium holdup and shielding content can be measured independently. 


\section{Experimental}

TEST SAT experiments were designed to assess the application of TEST to SATs to determine whether inspection criteria can be met and to perform a preliminary calibration of TEST. Experiments were performed on the Experimental SAT during the last quarter of 1986 , using the experimental TEST Scanner. During this period, the scanner was operated more than 160 hours, scanning 439 columns and collecting 6582 data sets. The TEST experiments were performed on an uncontaminated. empty SAT in 11 shielding configurations with three detector modes. Experiments also included plutonium holdup simulation measurements, resolution studies, and scanner geometry experiments designed to increase sensitivity by positioning the source module in the center void of the tank.

\section{DESCRIPTIONS}

\section{SAT}

A horizontal cross section of a fully shielded tank reveals six rings of shielding, three on each side of the annular solution region. (See Figure 1.) The inner and outer shielding are similar, each consisting of one ring of 3 -in.-thick high-density polyethylene (moderator) surrounded on each side by a ring of

FIGURE 1. SAT Full Shielding Configuration

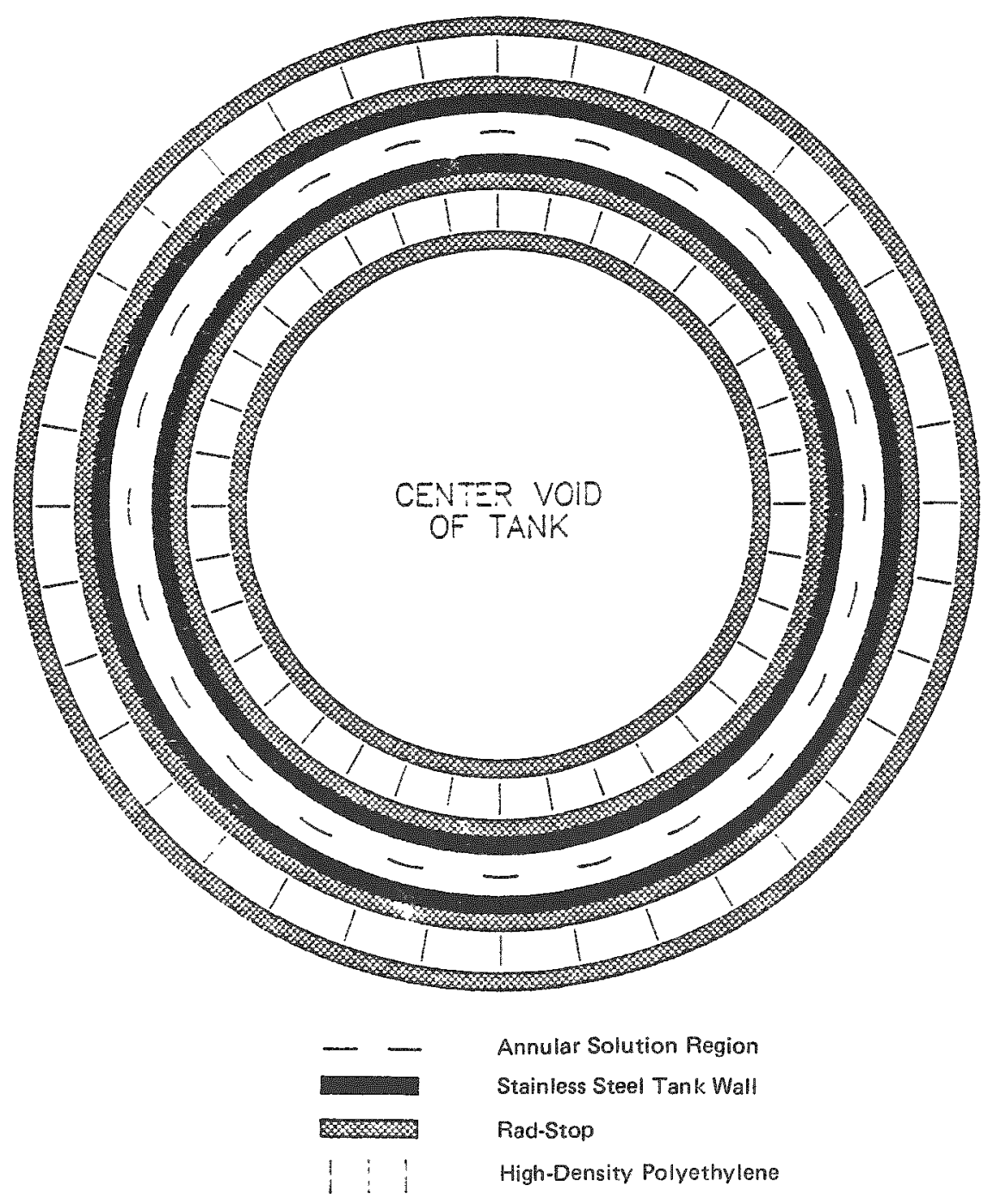


1/8-in.-thick Rad-Stop (neutron poison). The specifications for the Rad-Stop are listed in Appendix A. A vertical cross section of the SAT reveals 12 layers of shielding; each layer is a vertical half ( 180 degrees) of a ring. The tank itself was divided horizontally with a flange connecting the tank halves. The inner and outer polycthylene shielding was attached to the tank in quadrants.

For purposes of discussion. consider the tank with a grid superimposed. The 34 columns are labelled $0-33$; the rows are denoted " ". "0", "A", "B", " $C$ " thru " $N$ ". A region of interest (ROI) is labelled by these row-column coordinates, e.g., B,0. Each ROI defines a $6-\times 6$-in. area on the tank. The top of the tank is at Row 0 . and the bottom of the tank is at Row M. These 14 rows cover the full height of the tank. Therefore, the experimental SAT has 14 rows and 34 columns. Row " "is above the tank, Row $\mathbb{N}$ is below the tank. The flange is between Rows $F$ and $G$. For later discussion, note that Column 0 is located on the north side of the tank.

\section{TEST Automated Scanner}

The Experimental TEST Automated Scanner was designed and built by Custom Engineering, Inc. a Colorado-based engineering firm. The scanner is composed of three major components: The TEST ring. the source, and detector modules. The TEST ring is a geared track mounted to the top of a tank. The source and detector modules move independently around the track powered by stepping motors. The modules are suspended from the ring by a V-belt system. Each module has three dimensions of movement:

1. Clockwise/counterclockwise motion $\left(360^{\circ}\right.$ in $180^{\circ}$ increments)

2. Vertical motion to a maximum of $12 \mathrm{ft}$ below the ring

3. Two-step radial motion $(\sim 2 \mathrm{in}$. or $\sim 10 \mathrm{in}$. radially from the tank wall)

Figure 2 shows TEST mounted on the Experimental SAT. Appendix B contains a more complete list of the TEST equipment.

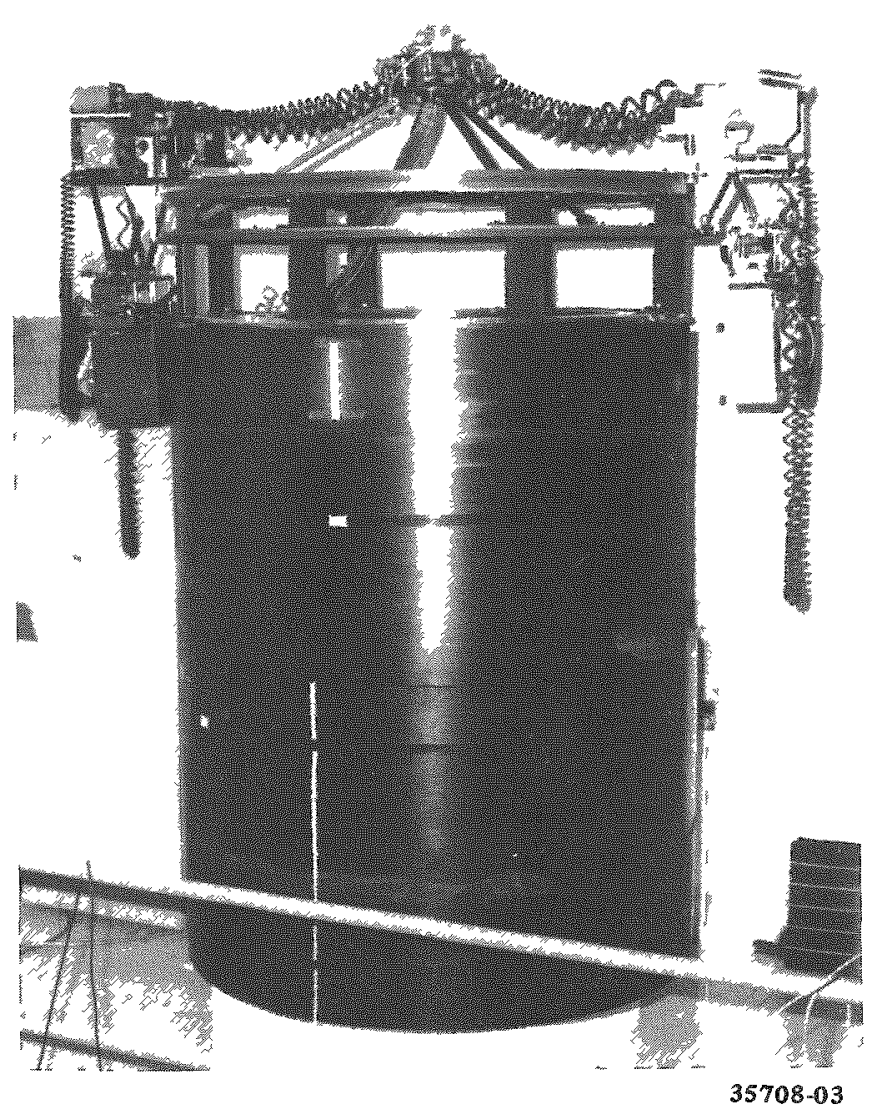

FIGURE 2. TEST Mounted on Experimental SAT

The source holder (Figure 3) was designed to maximize the front-to-back neutron flux ratio. The holder was a 7-in. cube of high-density polyethylene with the source positioned in the center of the cube's front face. Three nested cadmium boxes, opened on the front face. are interspaced in the polyethylene cube. Two helium-3 detectors, banked together, are aligned vertically on the back of the source. These detectors were not used in the SAT experments.

Six $6-X 1$-in. helium-3 detectors filled to $4 \mathrm{~atm}$ were banked together to create the detector module in the uncollimated mode. The detector holder was $14 \mathrm{in}$. high, $9 \mathrm{in}$. wide, and $3.5 \mathrm{in}$. deep. The individual detectors were separated by $1 / 4$ in. of polyethylene with $1 \mathrm{in}$. of polyethylene at the front and back. A 3-in. air space was located directly above the detectors for wiring. The polyethylene was surrounded on five sides by a 1/16-in. 


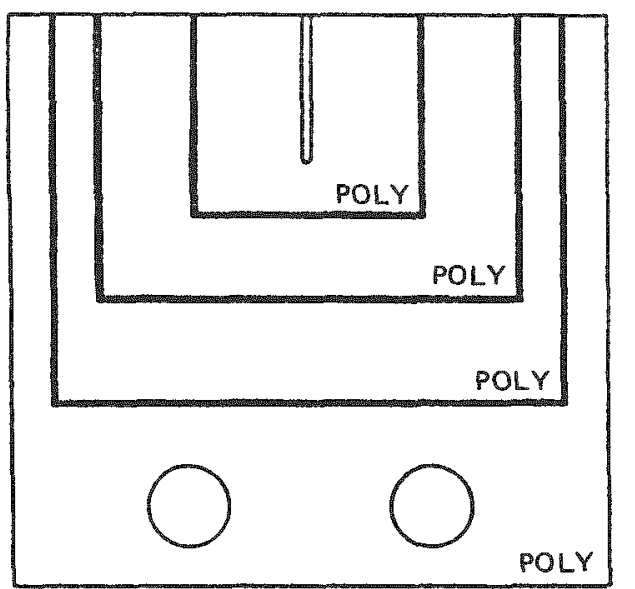

TOP

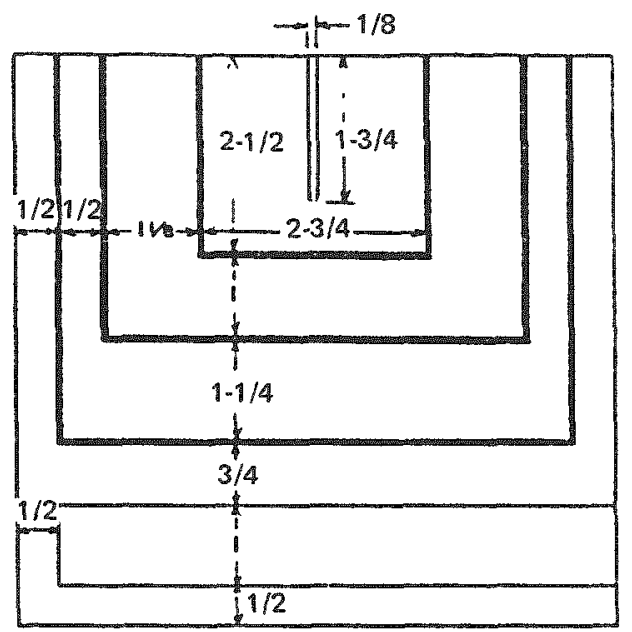

(dimensions in inches)

1/16-in. cadmium

FIGURE 3. TEST Source Holder

layer of cadmium. One-half inch of polyethylene then encased the cadmium. See Figure 4 for a cutaway view of the detector holder.

Three detector modes were studied during the TEST SAT experiments: (1) the uncollimated detector mode described previously, (2) the collimated detector mode. which was designed to reduce the background, and (3) the fast detector mode, which was designed to increase TEST sensitivity to missing polyethylene. To create the collimated detector mode, a 2-in.-thick block of polyethylene was attached above and below the active detector region of the detector module. The polyethylene blocks were lined, on the two faces near the module, with cadmium. The fast detector mode was made by attaching a piece of cadmium $(8 \times 13 \times 1 / 16 \mathrm{in}$. to the front face of the detector module. The cadmium absorbs thermal neutrons, allowing only fast neutrons to be moderated by the polyethylene and absorbed in the detectors. The collimated and fast detector modes are shown in Figures 5 and 6.

\section{Software}

The TEST Automated Scanner was controlled by a PDP $11 / 23+$ clone running the RSX $11 \mathrm{M}$-PLUS operating system. The programs were written in RSX FORTRAN-77 and Macro.

The scanning programs begin by initializing the scanner from a positional calibration mark affixed to the tank. (In Figure 2, the reflective tape on the top, middle of the tank is the calibration mark.) Once both modules found the mark. and the program retrieved the tank diameter from the database, the two modules were positioned diametrically opposed and at the same height. The program then moved the modules to each ROI on the tank. The ROI was labelled by the detector position, e.g. D. 6 indicates that the detector module was facing ROI D,6 with the source module diametrically opposed and at the same height. The tank was scanned beginning at the top of a column. The modules scanned down the column, stopping at each ROI to collect data. The modules then moved to the top of the current column before moving counterclockwise to the next column.

At each ROI, a set of data points was taken. Each data set was averaged and statistically analyzed. If the standard deviation was greater than allowed ( $2.5 \sigma$ for these experiments), the ROI was automatically re-assayed. For the SAT experiments. 


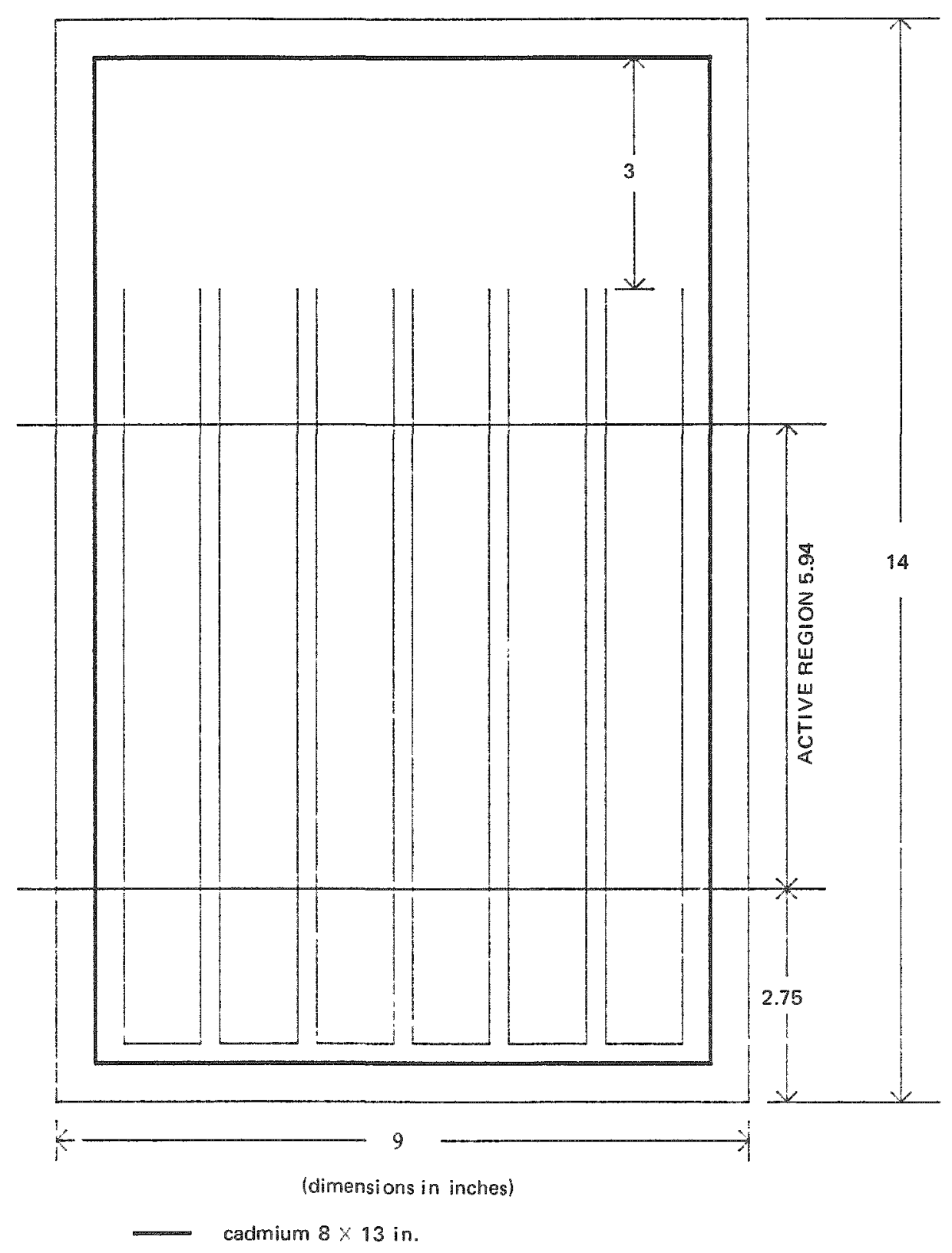

FIGURE 4. TEST Detector Holder

ach data set contained three 20 -second data points for a total assay time of 1 minute per ROI.

\section{Data Analysis}

Several programs were written to help perform data reduction and analysis. One program computed row and column averages and standard deviations.
Another program. SATERR, computed row and column sums and the corresponding $1-\sigma$ uncertainty. SATERR also interactively computed sums for the given intersection of rows and columns. See Appendix C for a sample output from "SATERR."

Data from the TEST scans were processed through SATERR, and region sums were compared. Two shiclding configurations were determined to be 


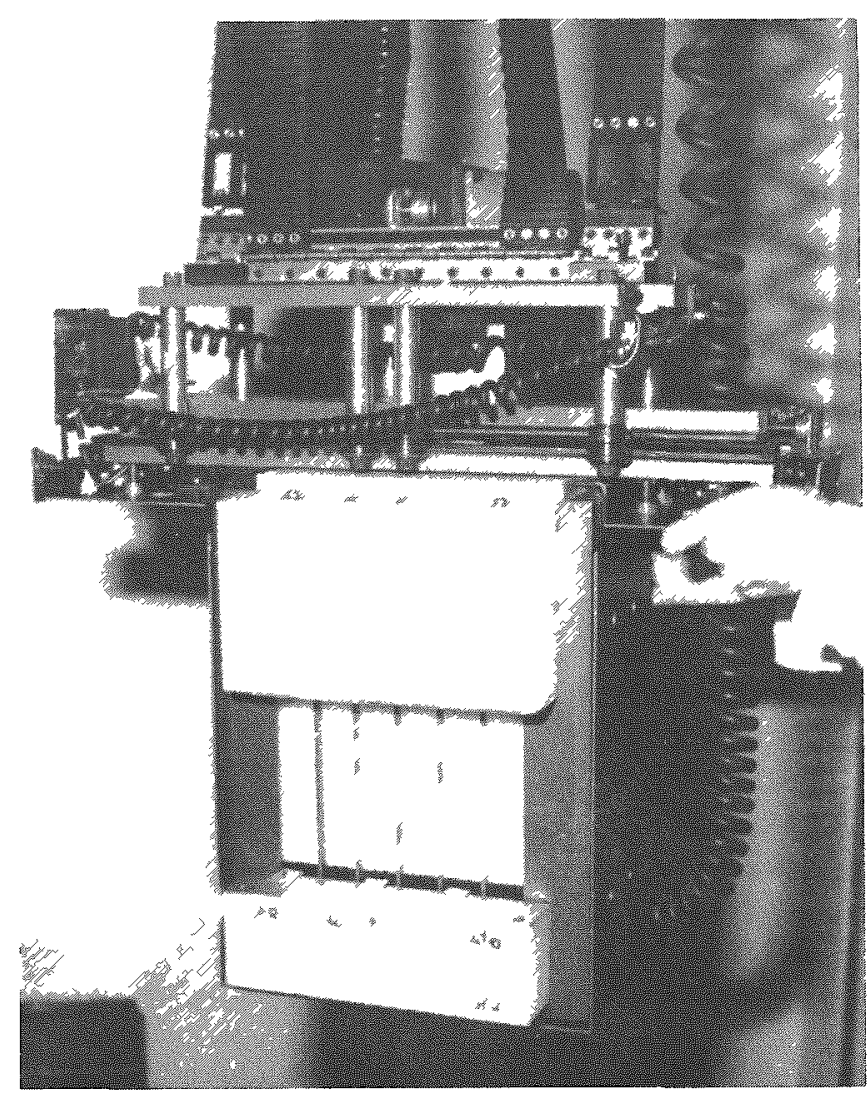

35708-18

FIGURE 5. TEST Detectors in the Collimated Mode

different when the difference between the region sums was greater than the $2-\sigma$ uncertainty. Appendix D provides examples of the uncertainty propagation and the comparison of two sums.

\section{SHIELDING VERIFICATION}

\section{Experiments}

Because of time constraints, the shielding verification experiments were performed as the tank shielding was assembled. Therefore, the full

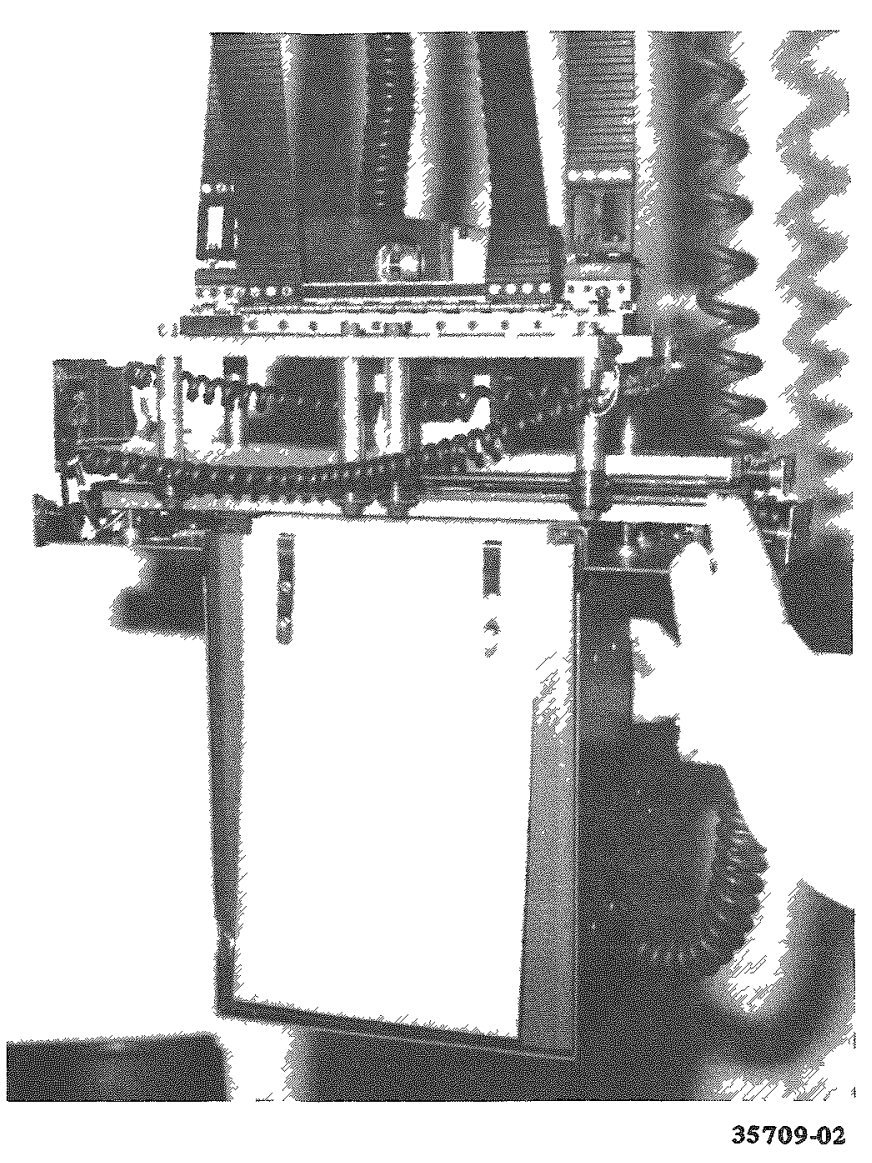

FIGURE 6. TEST Detectors in the Fast Mode

shielding configuration experiments were performed near the end of the experimentation.

Several smaller pieces of the shielding components were made available for use in the TEST SAT experiments. These were

1. Rad-Stop, $24 \times 64 \times 1 / 8 \mathrm{in}$.

2. Polyethylene, $12 \times 16 \times 3$ in.

3. Polyethylene, $12 \times 12 \times 3$ in., missing a prece $(4 \times 4 \times 3$ in.) along the center of one side. (See Figure 7.)

4. Polyethylene, $12 \times 36 \times 1 \mathrm{in}$. to simulate $20 \%$ of the polyethylene missing in one column. 

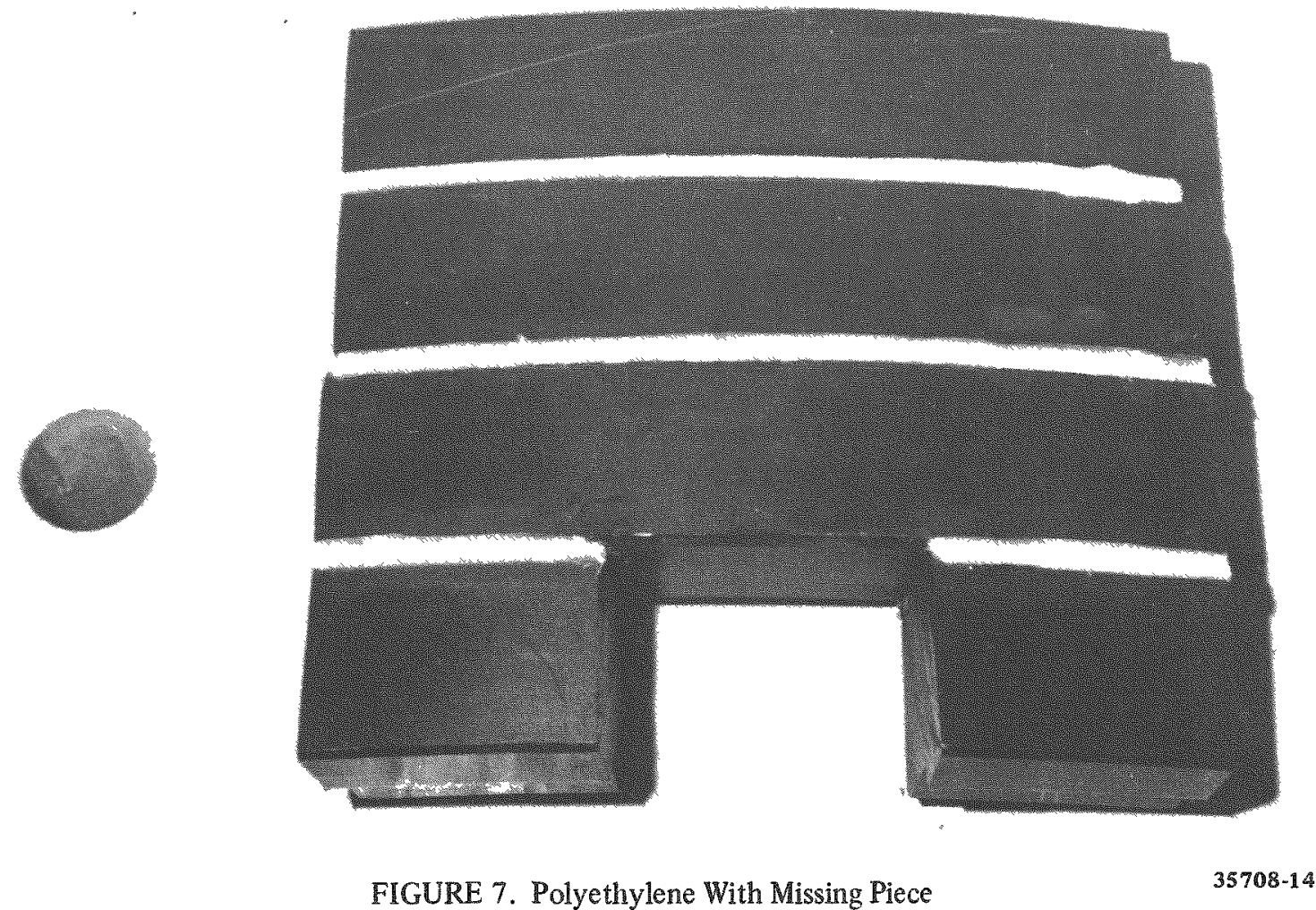

The thickness of the $20 \%$ piece was calculated as $30 \%$ of the thickness of one layer of polyethylene. Therefore, when the $20 \%$ piece was placed on the tank opposite one layer of polyethylene, $20 \%$ of the polyethylene was missing from one column, i.e., $50 \%$ of the polyethylene from one layer $+30 \%$ from the piece $=80 \%$ of the polyethylene $=20 \%$ of the polyethylcne missing.

Descriptions of the shielding define three separate areas: top outside, bottom outside, and the inside. The cleven shielding configurations and corresponding detector modes are outlined in Table 1 and further depicted in Figures 8 thru 11.

Scanner geometry experiments were also performed. The geometry of the scanner was changed by positioning the source module in the center void of the tank (not in the solution region). See Figure 1 to locate the center void. The source module was suspended from an overhead crane and positioned manually. Column 0 of the tank with full shielding configuration was scanned in this manner.

\section{Results}

Several sets of scans were performed on identical shielding configurations to test scan data repeatability. These scans included shielding Configuration 4 in the uncollimated detector mode and Configurations 7 and 12 in the collimated detector mode. Data from these scan sets were statistically alike for any row or column of the tank, thereby showing the scanner's ability to repeat scan data on identical shielding configurations.

The uncollimated and collimated detector modes were compared in scans of shielding Configurations 2.3. and 4. Background and end effects were more prevalent in the uncollimated detector mode data than in the collimated detector mode data. For this reason, scans with the uncollimated detector mode were discontinued after shielding Configuration 4: all remaining shielding configurations were scanned in the collimated and fast detector modes only. All results are from collimated detector mode unless nored. 
Configuration

1

2

3

4

5

6

7

8

9

10

11

12

TABLE 1. TEST SAT Shielding Configuration Experiments

Shielding Description

Top: None - tank wall exposed

Bottom: Inner Rad-Stop and poly

Inside: Inner Rad-Stop (near tank), poly, and 3 strips Rad-S top ${ }^{2}$

Top: Rad-Stop piece $(24 \times 68 \mathrm{in}$. affixed to south side, two poly pieces at Col $1^{b}$

Bottom: Inner Rad-Stop and poly

Inside: Inner Rad-Stop (near tank), poly, and 3 strips Rad-Stop ${ }^{a}$

Top: North $180^{\circ}$ of inner Rad-Stop and poly added to top Configuration $2^{c}$

Bottom: Inner Rad-Stop and poly

Inside: Inner Rad-Stop (near tank), poly, and 3 strips Rad-Stop ${ }^{a}$

Top: North $180^{\circ}$ of inner Rad-Stop and poly

Bottom: Inner Rad-Stop and poly

Inside: Inner Rad-Stop (near tank), poly, and 3 strips Rad-S top ${ }^{\mathrm{a}}$

Top: Rad-Stop added to south side of top Configuration 4

Bottom: Inner Rad-Stop and poly

Inside: Inner Rad-Stop (near tank), poly, and 3 strips Rad-Stop ${ }^{a}$

Equipment malfunction, repeated Configuration 10

Top: Inner Rad-Stop and poly

Bottom: Inner Rad-Stop and poly

Inside: Inner Rad-Stop (near tank), poly, and 3 strips Rad-S top ${ }^{2}$

Top: Inner Rad-Stop and poly

Bottom: Inner Rad-Stop and poly

Inside: Complete-Rad-Stop, poly, Rad-Stop

Top: Complete - Rad-Stop, poly, Rad-Stop

Bottom: Complete - Rad-Stop, poly, Rad-Stop

Inside: Complete - Rad-Stop, poly, Rad-Stop

Top: North $180^{\circ}$ of inner Rad-Stop and poly. Rad-Stop, $20 \%$ poly picce, Rad-Stop on south second Column CCW

Bottom: Inner Rad-Stop and poly

Inside: Complete - Rad-Stop, poly, Rad-Stop

Top: Configuration 10 with outer Rad-Stop on $20 \%$ piece removed

Bottom: Inner Rad-Stop and poly

Inside: Complete - Rad-Stop, poly, Rad-Stop

Top: Configuration 11 with inner Rad-Stop on $20 \%$ piece removed

Bottom: Inner Rad-Stop and poly

Inside: Complete - Rad-Stop, poly, Rad-Stop

\begin{tabular}{|c|c|c|}
\hline Detector Mode & Scans & Columns \\
\hline $\begin{array}{l}\text { uncollimated } \\
\text { fast }\end{array}$ & $\begin{array}{l}2 \\
1\end{array}$ & $\begin{array}{l}13,16 \\
11\end{array}$ \\
\hline $\begin{array}{l}\text { uncollimated } \\
\text { collimated }\end{array}$ & $\begin{array}{l}1 \\
1\end{array}$ & $\begin{array}{l}6 \\
2\end{array}$ \\
\hline $\begin{array}{l}\text { uncollimated } \\
\text { collimated } \\
\text { fast }\end{array}$ & $\begin{array}{l}1 \\
2 \\
1\end{array}$ & $\begin{array}{l}6 \\
6,13 \\
6\end{array}$ \\
\hline $\begin{array}{l}\text { uncollimated } \\
\text { collimated }\end{array}$ & $\begin{array}{l}2 \\
1\end{array}$ & $\begin{array}{l}2.2 \\
6\end{array}$ \\
\hline $\begin{array}{l}\text { collimated } \\
\text { fast }\end{array}$ & $\begin{array}{l}1 \\
2\end{array}$ & $\begin{array}{r}34 \\
6,4\end{array}$ \\
\hline $\begin{array}{l}\text { collimated } \\
\text { fast }\end{array}$ & $\begin{array}{l}2 \\
1\end{array}$ & $\begin{array}{c}9.16 \\
12\end{array}$ \\
\hline$\underset{\text { fast }}{\text { collimated }}$ & $\begin{array}{l}1 \\
1\end{array}$ & $\begin{array}{l}34 \\
13\end{array}$ \\
\hline $\begin{array}{l}\text { collimated } \\
\text { fast }\end{array}$ & $\begin{array}{l}2 \\
1\end{array}$ & $\begin{array}{l}34,11 \\
34\end{array}$ \\
\hline$\underset{\text { collimated }}{\text { cast }}$ & $\begin{array}{l}1 \\
1\end{array}$ & $\begin{array}{l}6 \\
6\end{array}$ \\
\hline $\begin{array}{l}\text { collimated } \\
\text { fast }\end{array}$ & $\begin{array}{l}1 \\
1\end{array}$ & $\begin{array}{r}34 \\
6\end{array}$ \\
\hline collimated & 2 & 36,6 \\
\hline
\end{tabular}

3,16

6,13 a. Rad-Stop placement, Figure 8 .

b. Poly and Rad-Stop placement. Figure 9. c. Configuration 3 shiclding (top view). Figure 10 .

d. 20 c poly placement, Figure 11 . 


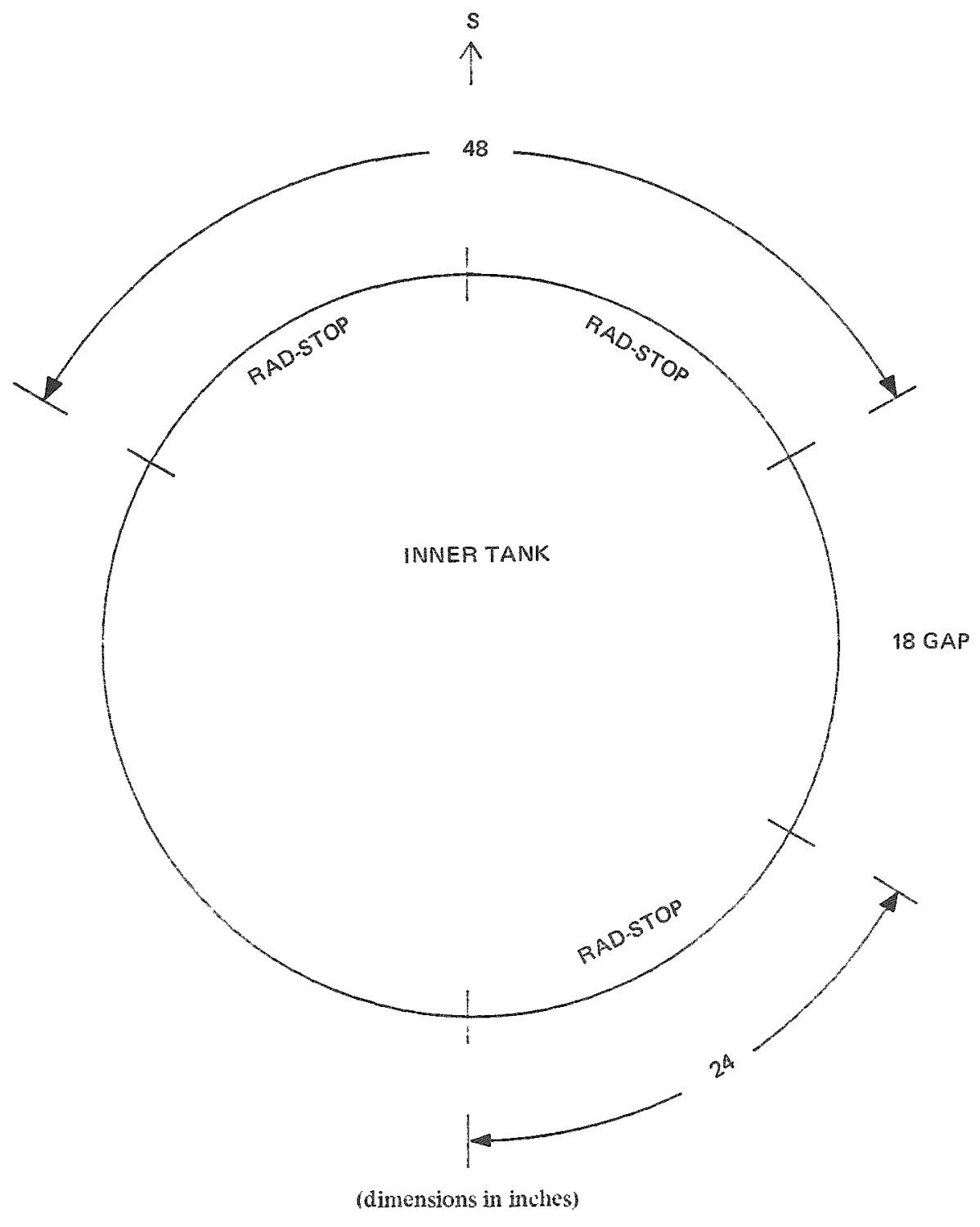

FIGURE 8. Rad-Stop Configuration for Inner Tank

The scanner geometry experiments with the source positioned in the center void of the tank increased the sensitivity of the TEST scanner. Scanning down a column, the count rates recorded at each $R O I$ with the source positioned inside the tank were 5 to 20 times greater than the comparable counts with the source outside the tank. A $2000 \%$ increase was recorded at the flange area where the polyethylene layer was thinner. This dramatic increase demonstrated the increased sensitivity of the TEST when the source module was positioned inside the tank. A 500 , increase occurred at the top and bottom of the tank. There the count rate with the source moduls positioned outside the tank was high because of neutron scattering around the extremities of the tank. The average count rate was 11 times greater with the source module inside the center void than with the source moduk outside the tank.

Data from Column 0 with the source module inside the tank are graphed in Figure 12. Data from the average fully shielded column with the source outside the tank are shown in Figure 13. 
FIGURE 9. SAT Shielding Configuration 2
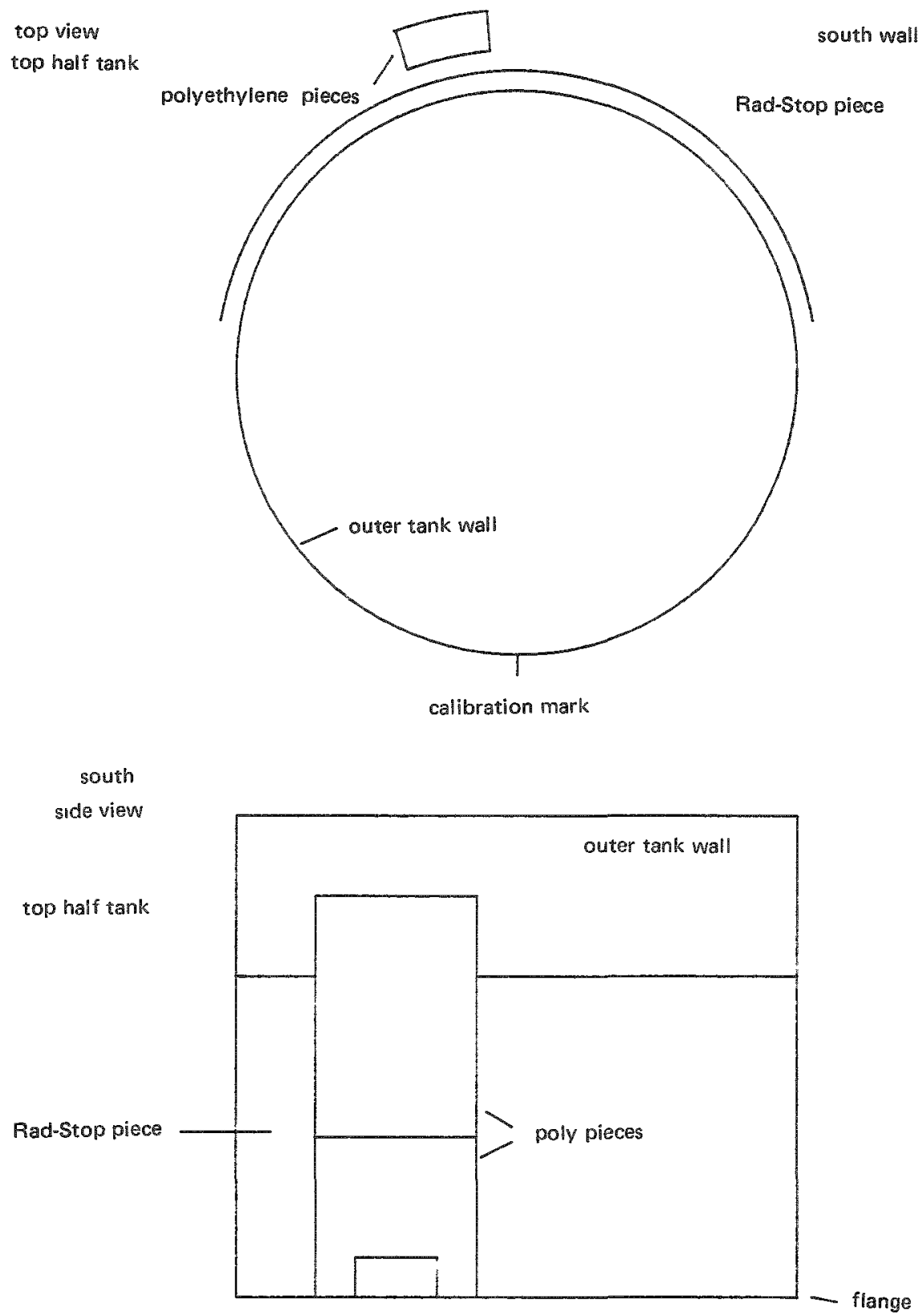
RFP-4165

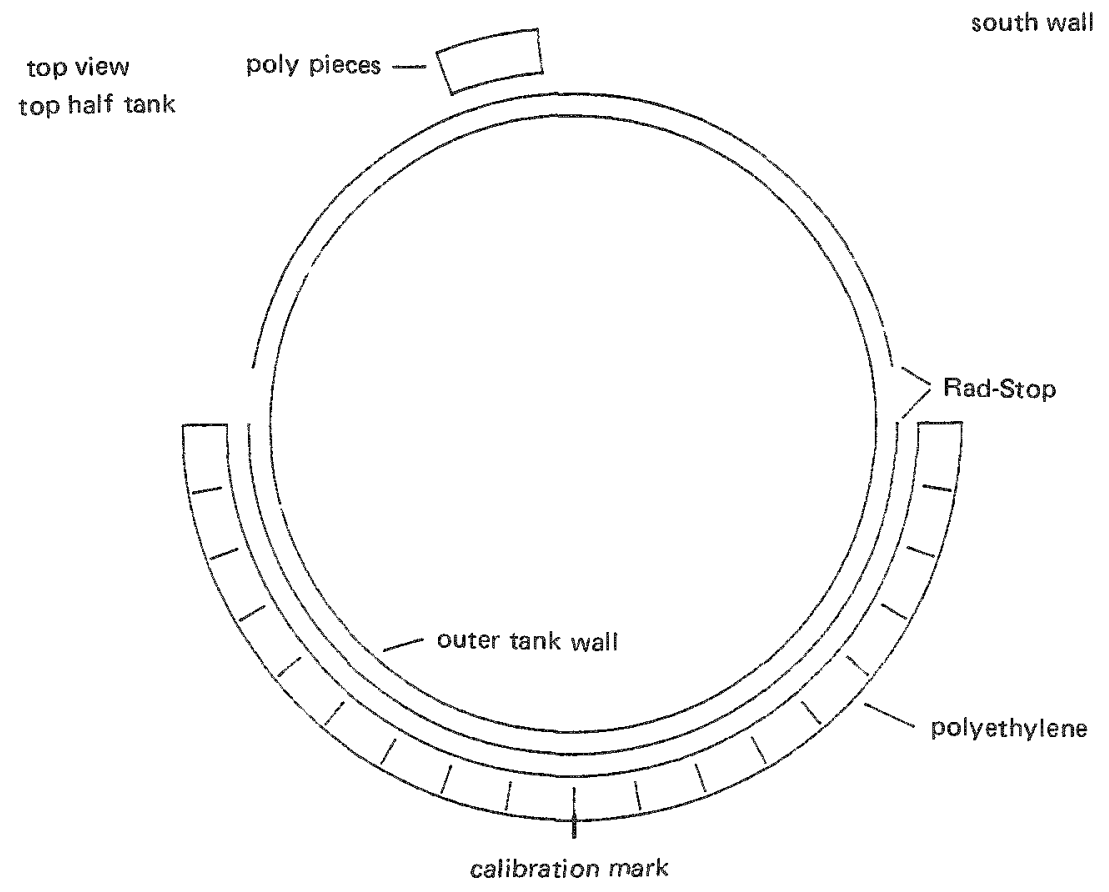

FIGURE 10. SAT Shielding Configuration 3

FIGURE 11. SAT Shielding Configuration 10

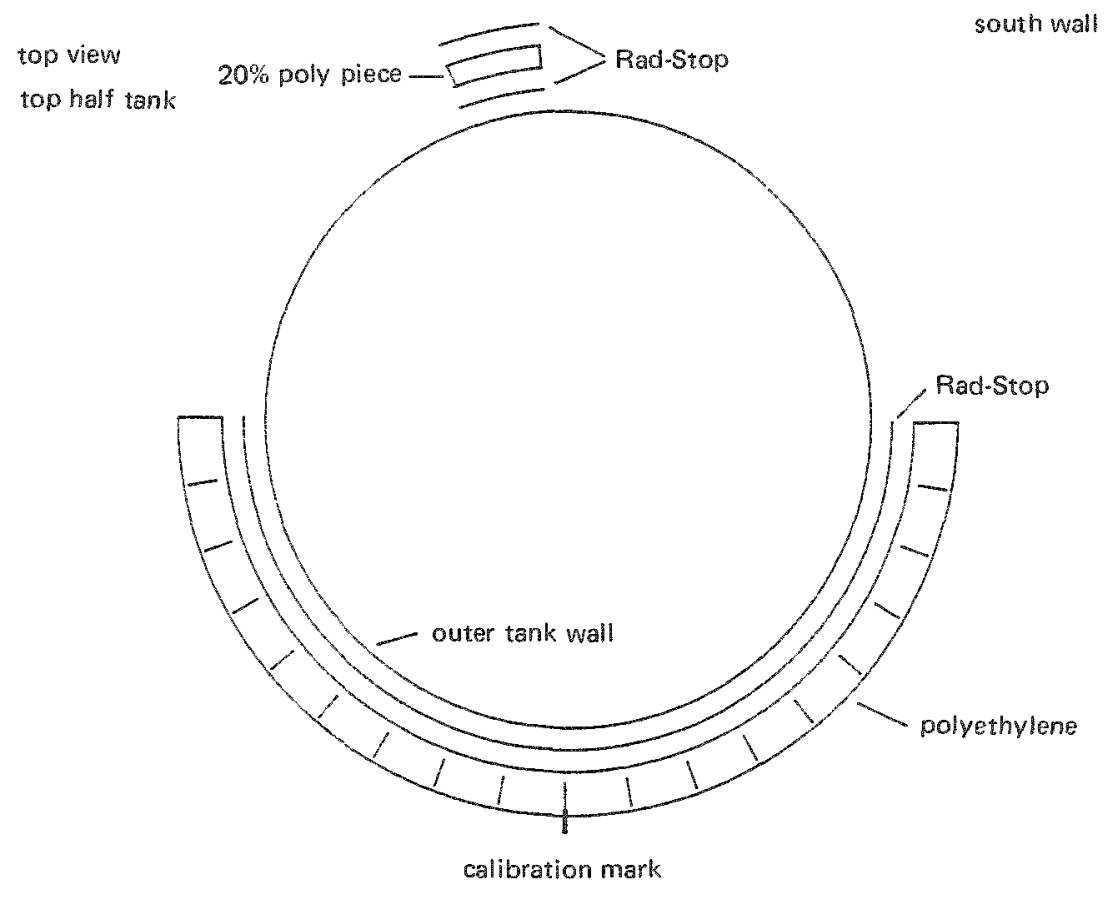




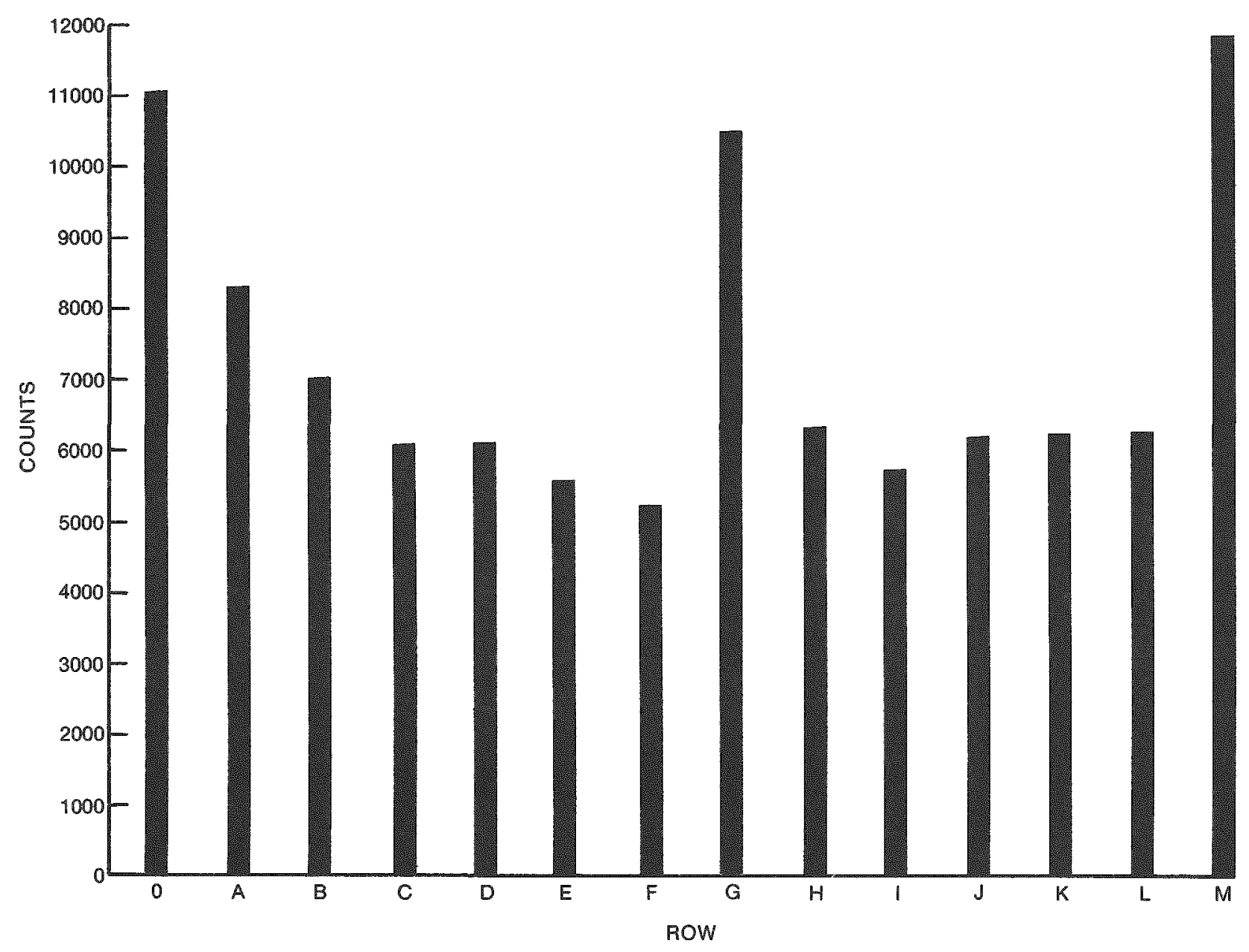

FIGURE 12. Experimental SAT, Column 0

Source Inside Tank

Experiments were performed to analyze TEST's sensitivity to missing Rad-Stop. The objective was to determine whether missing one ring of Rad-Stop from the tank shielding could be detected. This scenario was tested using shielding Configurations 8 and 9. The counts from the tank missing the outer ring of Rad-Stop (Configuration 8, Figures 14 and 15) were compared with the counts from the fully shielded tank (Configuration 9. Figures 13 and 16). The trends of the data for both row and column averages are similar, with Configuration 8 counts consistently above Configuration 9 counts by $\sim 100$. This difference was statistically significant by row or column for the counting time and rates used in these experiments. Therefore, objective was met; the missing ring of Rad-Stop was detected.
Another set of experiments testing the TEST sensitivity to missing Rad-Stop involved Configurations 7 and 8 . Configuration 7 had approximately half the inner ring of Rad-Stop missing. Figure 8 shows the inner Rad-Stop configuration. In Configuration 8, the inner Rad-Stop ring was complete. The Configuration 7 counts summed over half the tank were significantly higher than the Configuration 8 counts. (Appendix D discusses the uncertainty propagation and determination of statistical significance.) In fact, the difference in count rates was still prevalent when summing only the top or bottom quarter of the tank. The difference was not statistically significant for a smaller area of the tank. However. the difference may be significant for smaller areas, such as an individual 


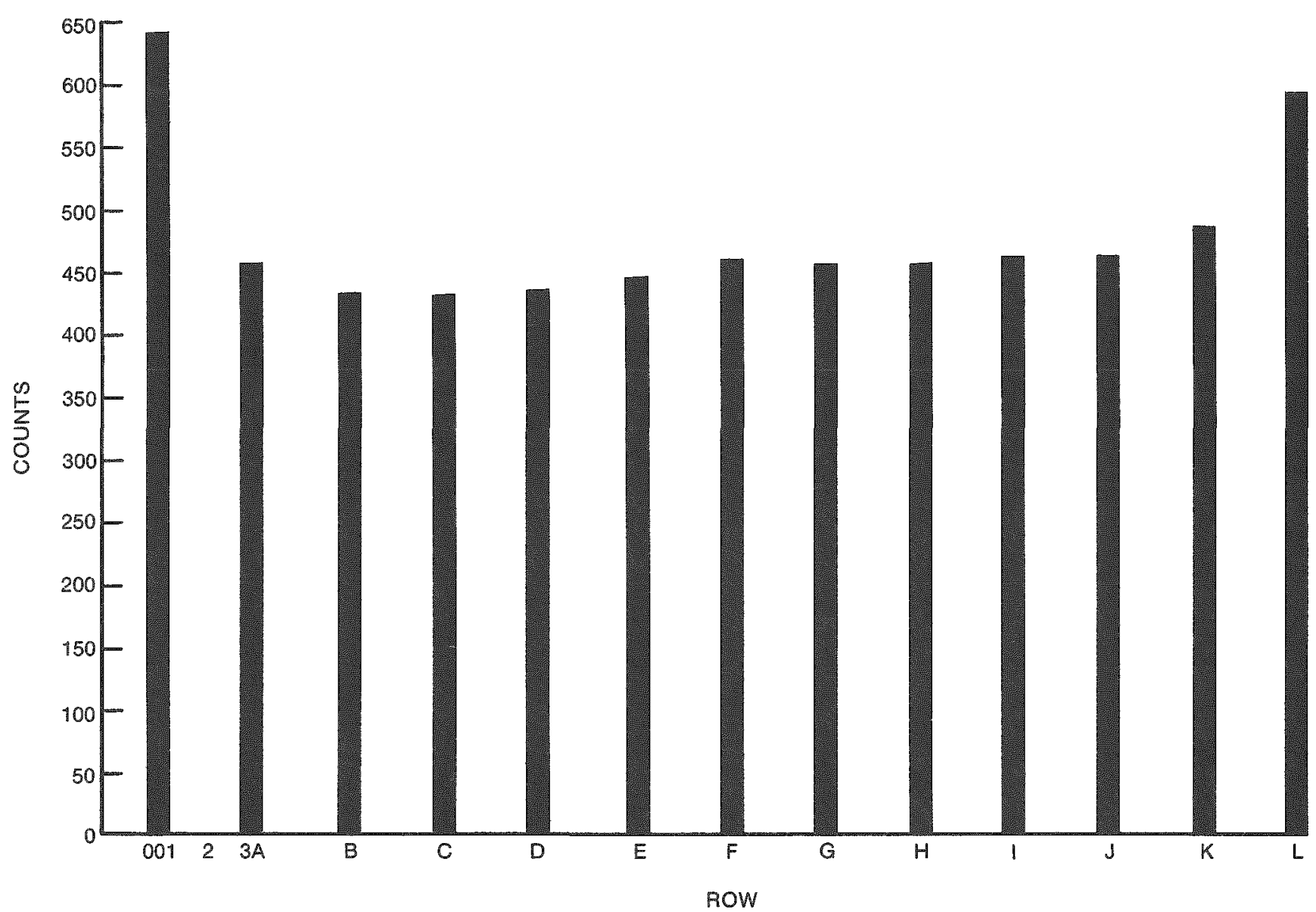

FIGURE 13. Experimental SAT, Configuration 9

Row Averages

row or column if the assay time is increased to improve the precision of the counting statistics.

A final scan set (in which the Rad-Stop was the variable) involved shielding Configurations 4 and 5 . For shielding Configuration $4,180^{\circ}$ of the inner Rad-Stop and polyethylene were attached to the top, outside the tank. Configuration 5 was identical with Configuration 4 with the addition of the Rad-Stop piece affixed to the south side of the tank. The Rad-Stop piece was only two feet high and, comparing the row sums, could easily be distinguished. The count sums could not be statistically differentiated at a $99 / \%$ confidence level for Rows $0, \mathbf{A}$, or $\mathbb{I}$ thru $\mathrm{M}$. The count rate sums were statistically different for Rows B thru $G$ where the Rad-Stop was located. The data from the first 16-1/2 columns were used for the comparison. See Table 2 for the complete list of sum differences.
The other objective of the shielding verification experiments was to determine the minimum loss of polyethylene that could be detected. Shielding Configurations 4 and 12 were similar except for the addition of the $20 \%$ polyethylene piece on Configuration 12. However, because of the large background difference. these two scans could not be directly compared.

Another set of experiments. Configurations 5 and 3 , dealt with the issue of $25 \%$ missing polyethylene. The difference in the two configurations was the addition of the polyethylene pieces for Contiguration 3. The first three columns of each tank half were used for the comparison. Count sums from the three column tank halves were statistically different at a $99 \%$ confidence level. Comparing tank quadrants, the sums from the bottom two quarters were not statistically different, while the top two 
FIGURE 14. Experimental SAT, Configuration 8

Row Averages

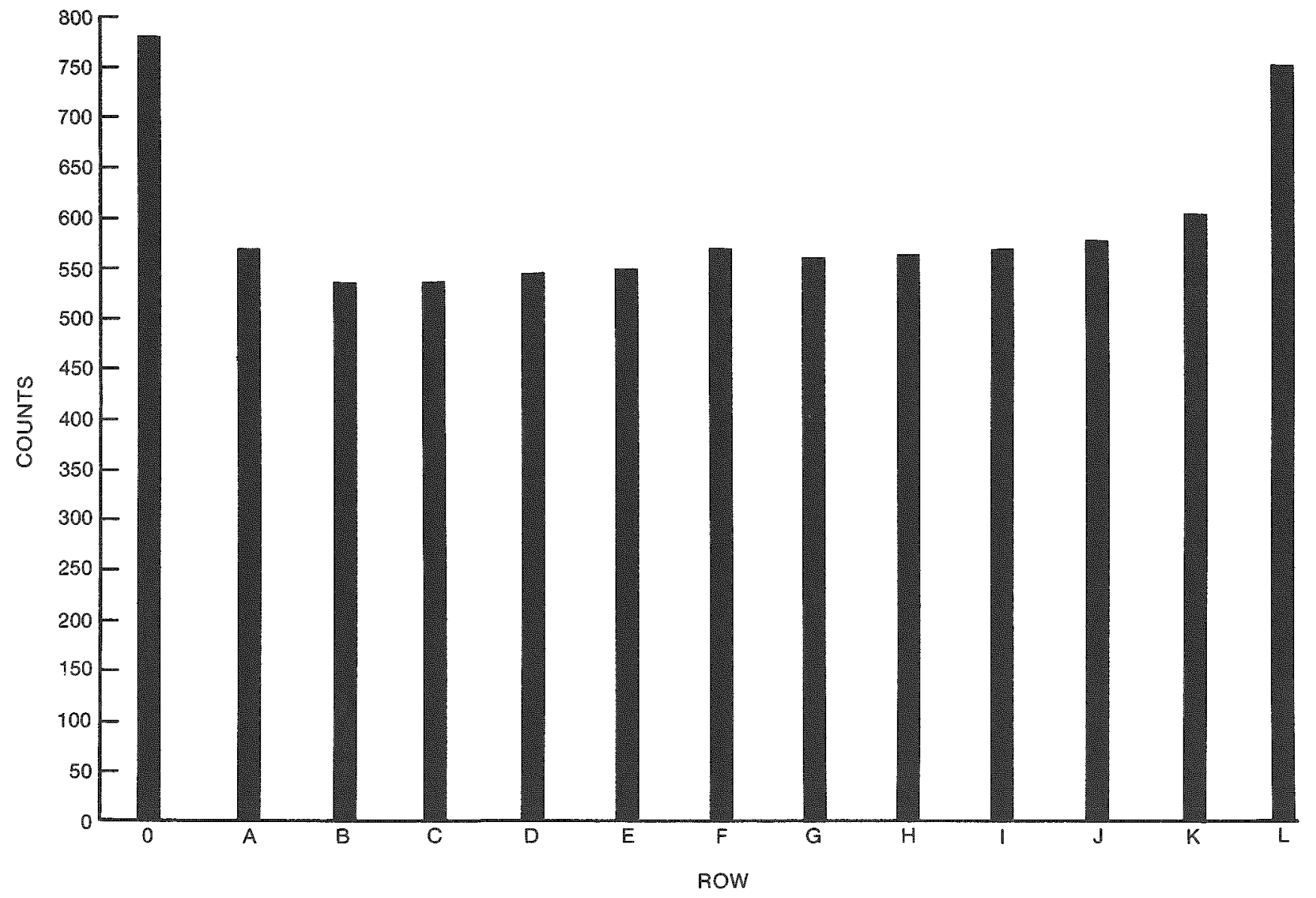


FIGURE 15. Experimental SAT, Configuration 8 Column Averages

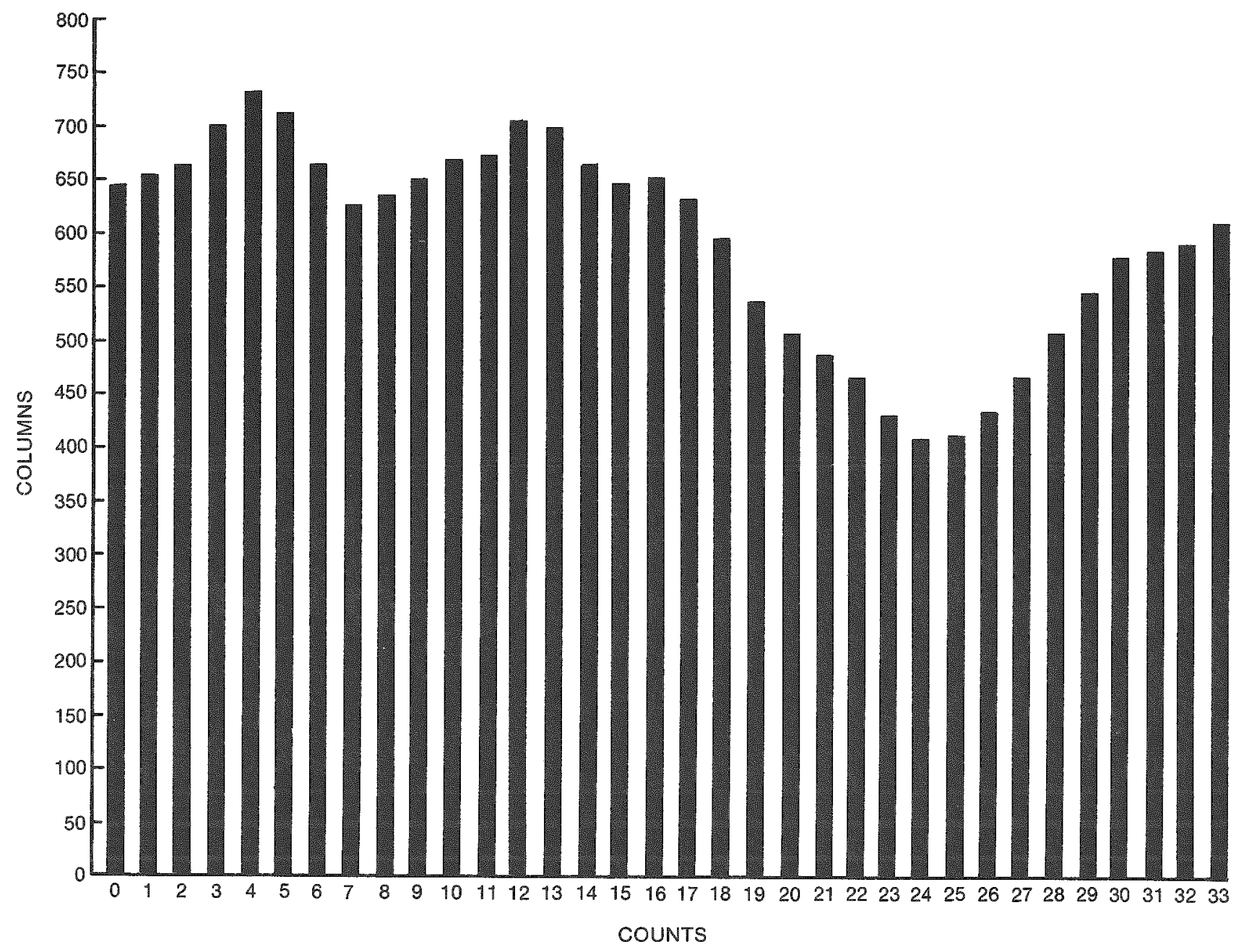


FIGURE 16. Experimental SAT, Configuration 9

Column Averages

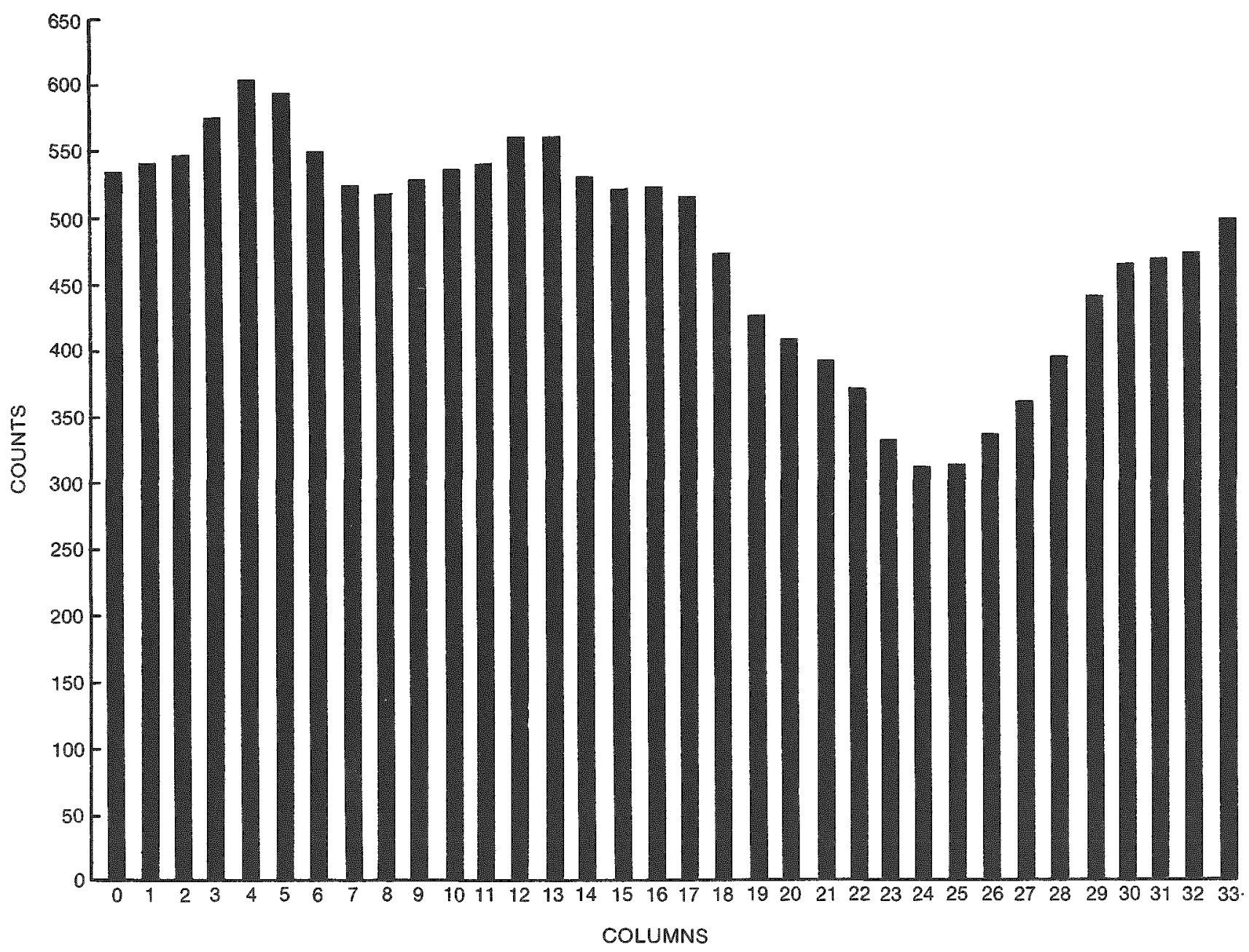


TABLE 2. Row Sum Difference

Difference $=$ Configuration 4 sum - Configuration 5 sum

\begin{tabular}{|c|c|c|c|}
\hline Row & $\begin{array}{c}\text { Difference } \\
\text { (counts) }\end{array}$ & $\begin{array}{c}\text { Uncertainty }(2 \sigma) \\
\text { (counts) }\end{array}$ & Rad-Stop \\
\hline 0 & -8 & 253 & no \\
\hline $\mathrm{A}$ & 54 & 221 & no \\
\hline $\mathrm{B}$ & 538 & 214 & yes \\
\hline $\mathrm{C}$ & 595 & 211 & yes \\
\hline $\mathrm{D}$ & 649 & 209 & yes \\
\hline $\mathbb{E}$ & 611 & 206 & yes \\
\hline $\mathrm{F}$ & 568 & 197 & yes \\
\hline$G$ & 250 & 177 & flange \\
\hline $\mathrm{H}$ & 221 & 172 & no \\
\hline I & -62 & 170 & no \\
\hline J & 123 & 170 & no \\
\hline $\mathrm{K}$ & 132 & 172 & no \\
\hline $\mathbf{L}$ & 49 & 190 & no \\
\hline $\mathrm{M}$ & 406 & 369 & no \\
\hline
\end{tabular}

quarters were different. Sums from the top two quarters of the Configuation 5 tank were statistically higher than the corresponding sums from the Configuration 3 data. This was the expected outcome: the top half of one column of Configuration 5 had 25\% more polyethylene, and shielding configurations on the bottom half of the tank were similar. Therefore. TEST could discern as little as $25 \%$ polyethylene missing.

The comparison was also made with the fast detector mode data. Each scan covered six columns, the first three columns on each half of the tank. The sum from each individual column of Configuration 5 was significantly higher than the corresponding sum from Configuration 3. Moving down the column and summing the rows, the Configuration 5 counts were significantly higher until Row H. At Row $H$, the difference was no longer discernable: this was expected since the shiclding configurations on the tank bottom were identical. Once again. the missing polyethylene was detected by the TEST. See Table 3 for the full result.

The scan data seem to show increased sensitivity to polyethylent in the fast detector mode. However. the scanner shows sufficient sensitivity to missing polyethylene in the collimated detector mode.
TABLE 3. Fast Detector Data

Difference $=$ Configuration 5 sum - Configuration 3 sum

\begin{tabular}{|c|c|c|c|}
\hline Row & $\begin{array}{c}\text { Difference } \\
\text { (counts) }\end{array}$ & $\begin{array}{l}\text { Uncertainty }(2 \sigma) \\
\text { (counts) }\end{array}$ & Shielding Difference \\
\hline 0 & 327 & 145 & yes \\
\hline A & 492 & 119 & yes \\
\hline $\mathrm{B}$ & 646 & 111 & yes \\
\hline C & 523 & 109 & yes \\
\hline $\mathrm{D}$ & 573 & 107 & yes \\
\hline $\mathrm{E}$ & 414 & 106 & yes \\
\hline$F$ & 294 & 104 & yes \\
\hline $\mathrm{G}$ & 114 & 97 & flange \\
\hline $\mathbb{H}$ & 43 & 95 & no \\
\hline I & 53 & 93 & no \\
\hline $\mathbf{J}$ & 12 & 94 & no \\
\hline $\mathbf{K}$ & 13 & 97 & no \\
\hline $\mathbf{L}$ & -20 & 112 & no \\
\hline $\mathbf{M}$ & 40 & 264 & no \\
\hline $\mathbb{N}$ & -66 & 506 & no \\
\hline
\end{tabular}

Therefore, the added cost in equipment, extra design effort, and data analysis to incorporate the fast detector mode into the scanner design do not seem worthwhile.

\section{RESOLUTION STUDIES}

\section{Experiments}

Resolution, or scattering, studies were performed on the fully shiclded tank configuration (Configuration $9)$ to determine the spatial resolution of the detectors. The source module was fixed at a specific ROI, and the detector module was moved vertically along the column or horizontally around a row. Two of the resolution study scans were performed with the source module positioned in the center void of the tank (Figure 1). referred to as "inside," in Table 4 concerning resolution studies.

\section{Results}

Figure 17 depicts data from the scan with the source module fixed at G,O (vertical center of the tank) and the detector module moving vertically along the height of the column. This scan had both source 
TABLE 4. TEST Resolution Studies

\begin{tabular}{|c|c|c|}
\hline Source Position & $\begin{array}{l}\text { Detector } \\
\text { Motion } \\
\end{array}$ & $\begin{array}{l}\text { Estent } \\
\text { of Travel }\end{array}$ \\
\hline 0.0 & vertically & Rows $0-N$ \\
\hline D. 0 & vertically & Rows $" 29-M$ \\
\hline $\mathrm{G}, 0$ & vertically & Rows $0-\mathbb{N}$ \\
\hline L. 0 & vertically & Rows $0-\mathbb{N}$ \\
\hline C. 0 & horizontally & CW 9. CCW 9 \\
\hline Inside* $\sim \mathrm{B}, \mathrm{O}$ & vertically & Rows $0-\mathrm{N}$ \\
\hline Inside $* \approx B, O$ & horizontally & CW $5, \mathrm{CCW} 3$ \\
\hline
\end{tabular}

*Source module positioned in the center void of the tank.

FIGURE 17. Experimental SAT, Resolution Studies

Source fixed at $\mathrm{G}, 0$

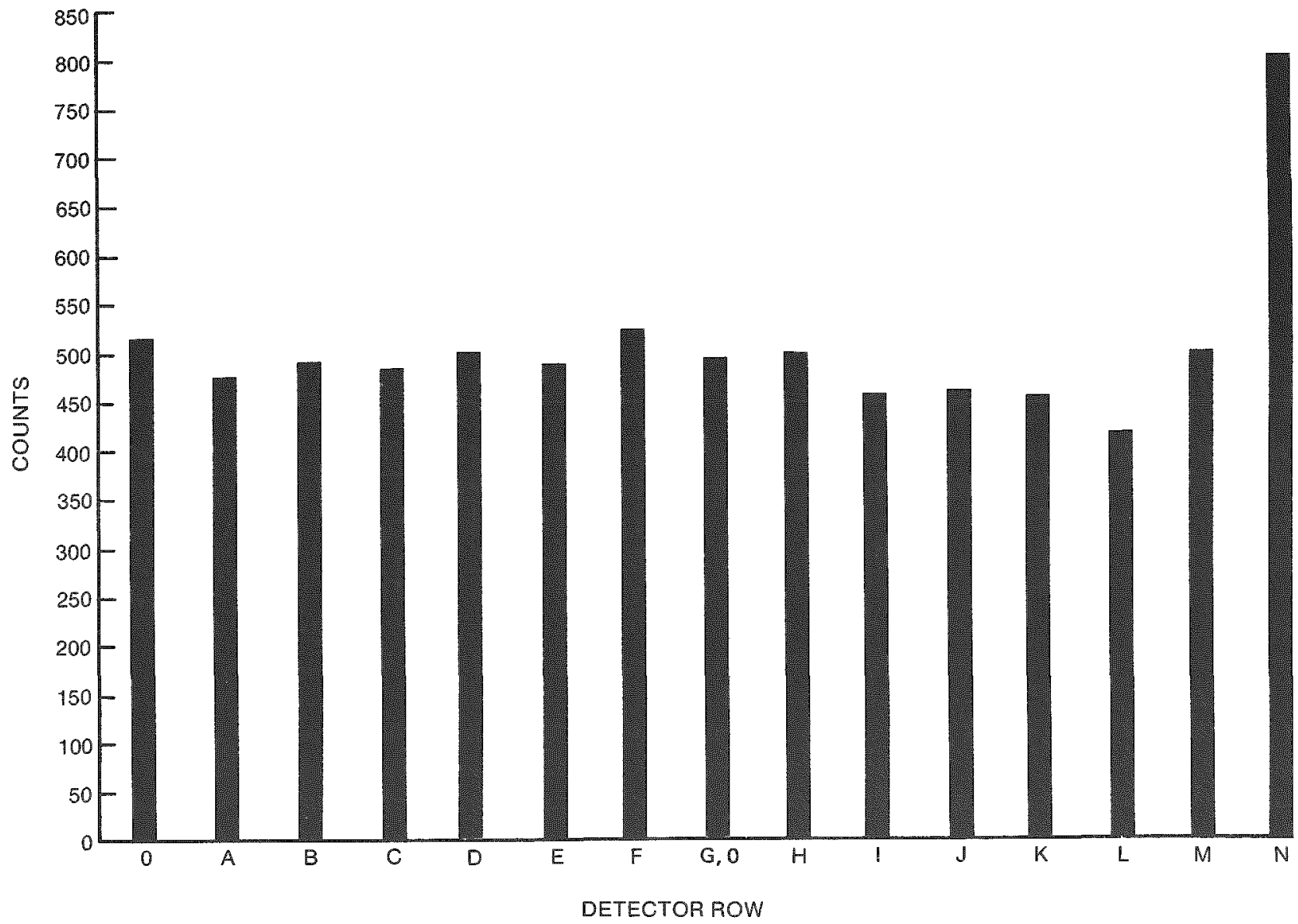


and detector modules outside the outer tank walls. The plot is flat, with the greatest increase in counts occurring when the detector module was at Row $L$. near the bottom of the tank. There the detectors were counting neutrons, which scattered around the bottom of tank. Otherwise. the counts recorded were not statistically different along the height of the column. This experiment showed that the neutrons were scattering fairly evenly throughout the height of the tank.

Keeping the source fixed and moving the detector horizontally around a row produced similar results. In fact. the counts were flat 12 in. ( 2 ROIs) on either side of the source and then began to increase. This increase was due to the decrease in the mean distance between the source and the detector modules as the detector module moved around the tank (toward the source module). This experiment showed the neutrons scattering throughout a horizontal slice of the tank. Therefore, since the neutrons scattered throughout the tank. the neutron poisons and moderators had to be missing over large areas to be detected by the scanner.

Moving the source module into the center void of the tank, however, greatly increased the resolution of the system. In one experiment. the source module was suspended inside the tank near position $\mathrm{B}, 0$. The detector module was moved vertically along the height of the column. Within $12 \mathrm{in.}$ (2 ROIs) above and below the source module, the count rate had been reduced by over $50 \%$; within $30 \mathrm{in.}$. only $5 \%$ of the original counts were detected. Therefore, changing the scanner geometry significantly increased the resolution of the scanner.

Moving the detector module horizontally around a row, while keeping the source fixed inside the tank, also showed increased sensitivity when compared with scan data with the source module outside the tank. The source was fixed between B. 0 and B.1. Within 6 in. on either side of the source (1 ROI), the count rate had been reduced more than 15\%. Fighteen inches away, the count rate was reduced approximately $75 \% ; 30 \mathrm{in}$. away. the count rate was only $10 \%$ of the original. With the source inside the center void of the tank, the resolution of the scamner was dramatically increased. both vertically and horizontally. This increased resolution was demonstrated by the fact that the missing polyethylene in the flange area was detectable when the source module was positioned in the center roid of the tank and undetectable when the source module was positioned outside the tank.

\section{SOURCE-SIMULATED HOLDUP}

\section{Experiments}

Experiments were performed to determine whether the TEST Scanner could be used for holdup detection for criticality safety purposes. Experiments were performed in an effort to determine if $2500 \mathrm{~g}$ or more of plutonium holdup present in the tank would be detectable. In the worse case for criticality considerations, the holdup would be in one small area of the tank. To simulate this situation. a californium-252 neutron source was suspended in the annular solution region of the tank at approximately ROI, L.2.

During these experiments, the source strength was approximately $3.67 \times 10^{5}$ neutrons per second. Two scans of the tank were performed: (1) a holdup scan with the detector module only (no source module present) and (2) a boron scan with both the source and detector modules present. The holdup scan was a full, 15-row by 34-column scan. The boron scan was only 19 columns by 15 rows due to time constraints. Data collected from the two scans were similar and could be compared over half the tank. The row average for each column is shown in Figures 18 and 19. The ROI averages for Column 2 for both the holdup and boron scans are shown in Figures 20 and 21. From these experiments, the detector efficiency was calculated as $0.07 \%$ determined from the equation:

$$
\begin{aligned}
& 4874 \text { neutrons at the detectors/ } \\
& \frac{20 \text {-second assay time }}{3.67 \times 10^{5} \text { neutrons per second }}=0.0007
\end{aligned}
$$

\section{Results}

The plots of the data (Figures 18-21) show definite count rate peaks at the position of the sourcesimulated plutonium holdup. This demonstrates the 
RFP-4165

FIGURE 18. Experimental SAT, Configuration 9

Holdup Scan, Source-simulated Holdup

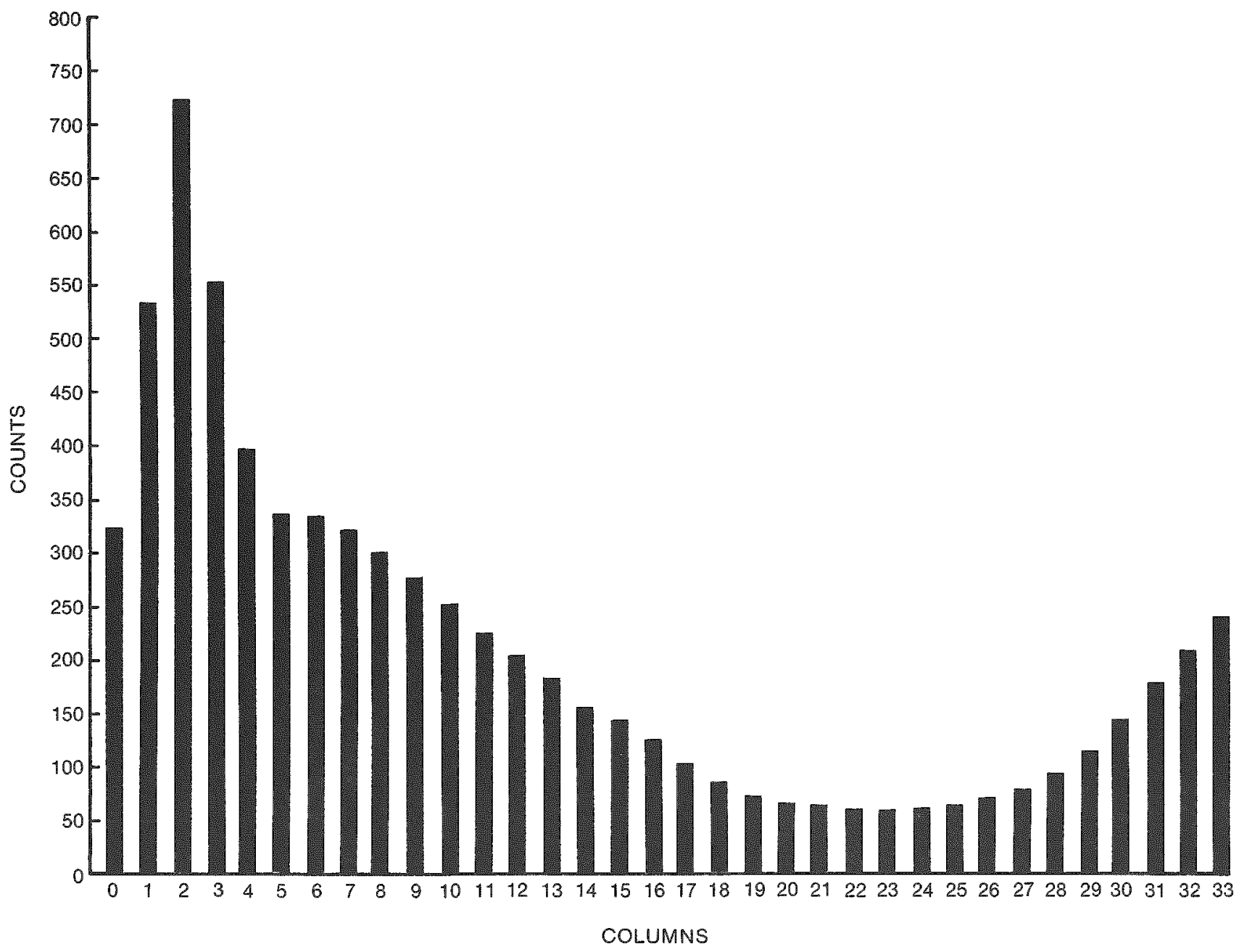


RFP-4165

FIGURE 19. Experimental SAT, Configuration 9

Boron Scan, Source-simulated Holdup

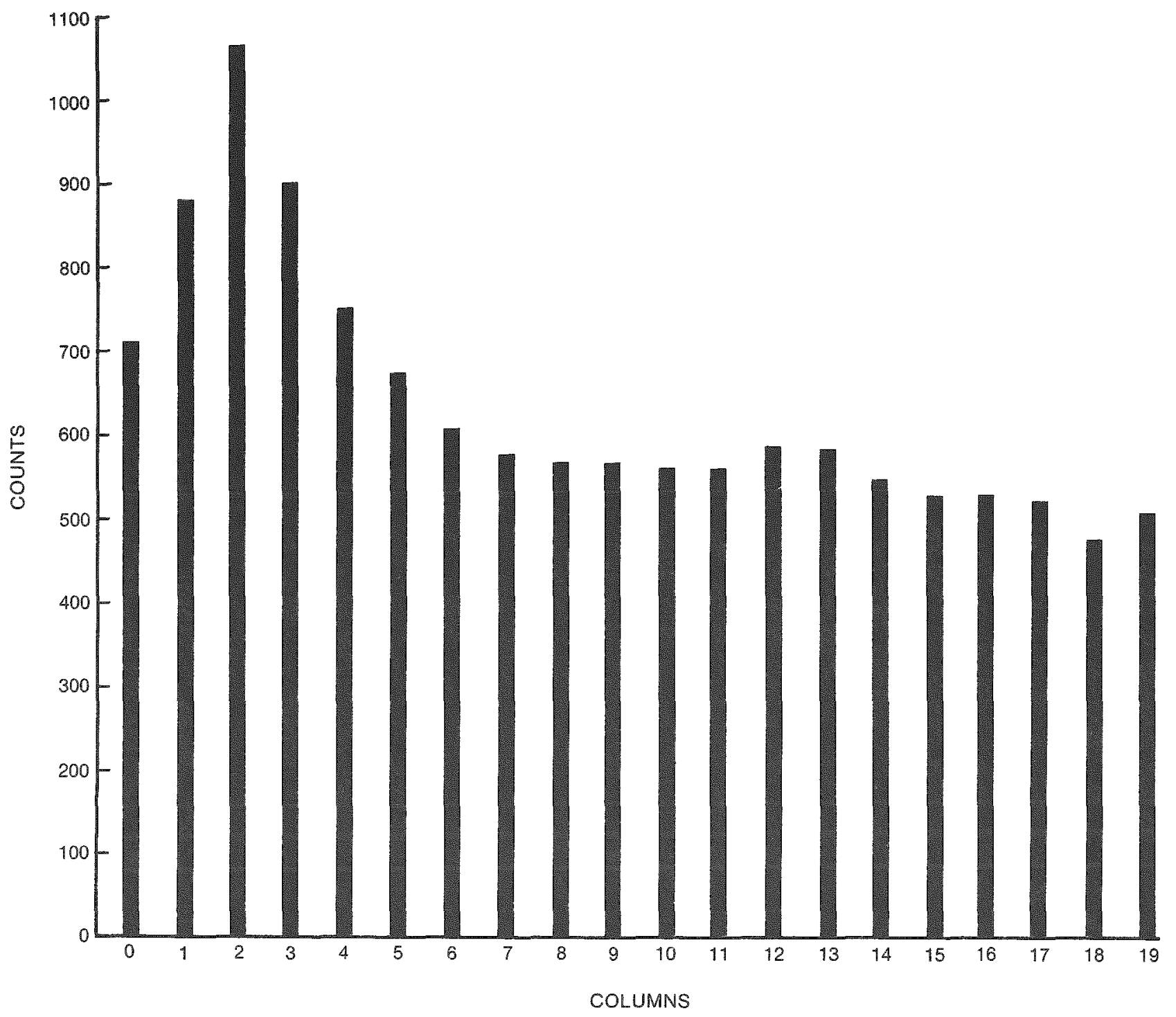


RFP-4165

FIGURE 20. Experimental SAT, Source-simulated Holdup Holdup Scan, Column 2

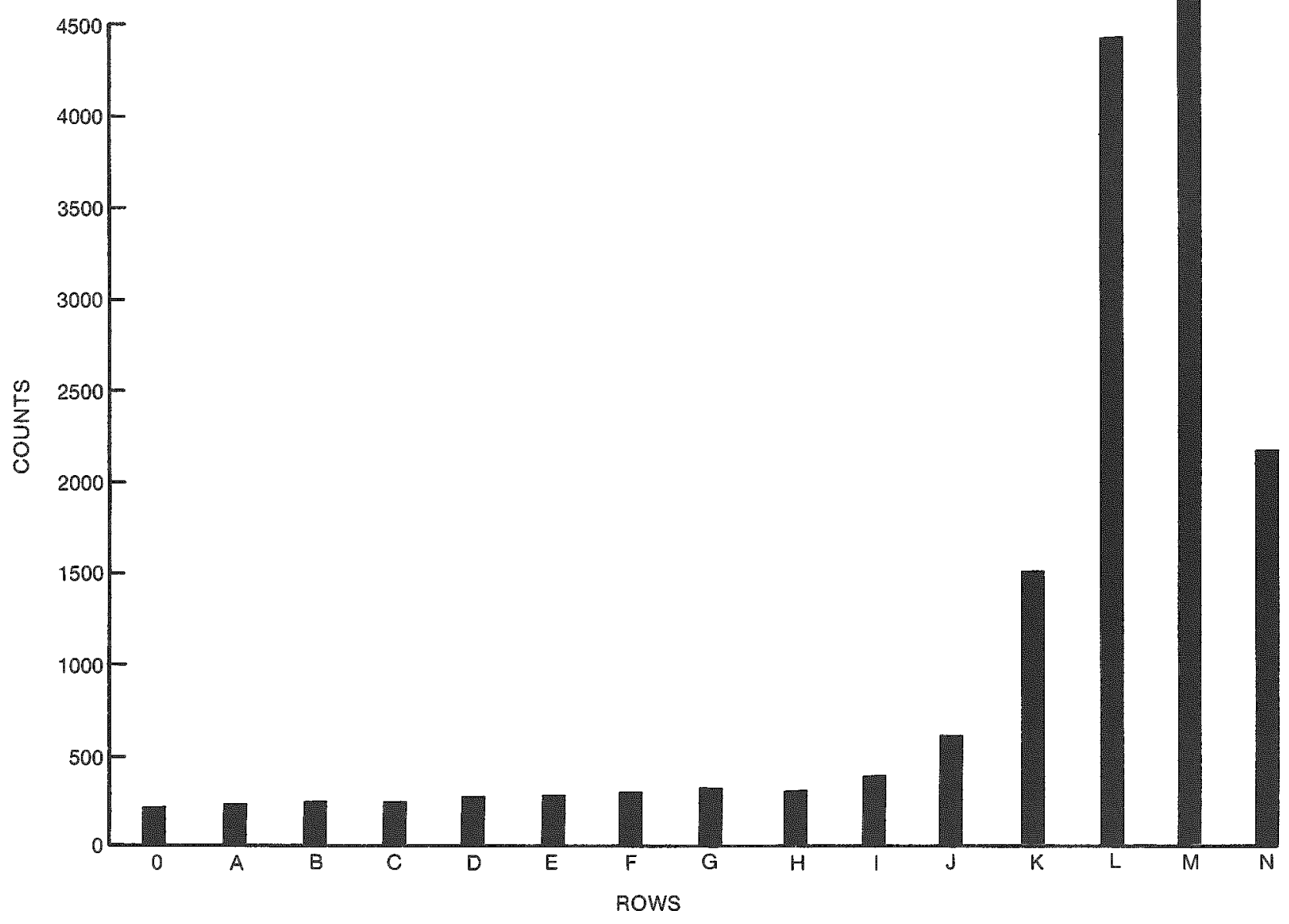




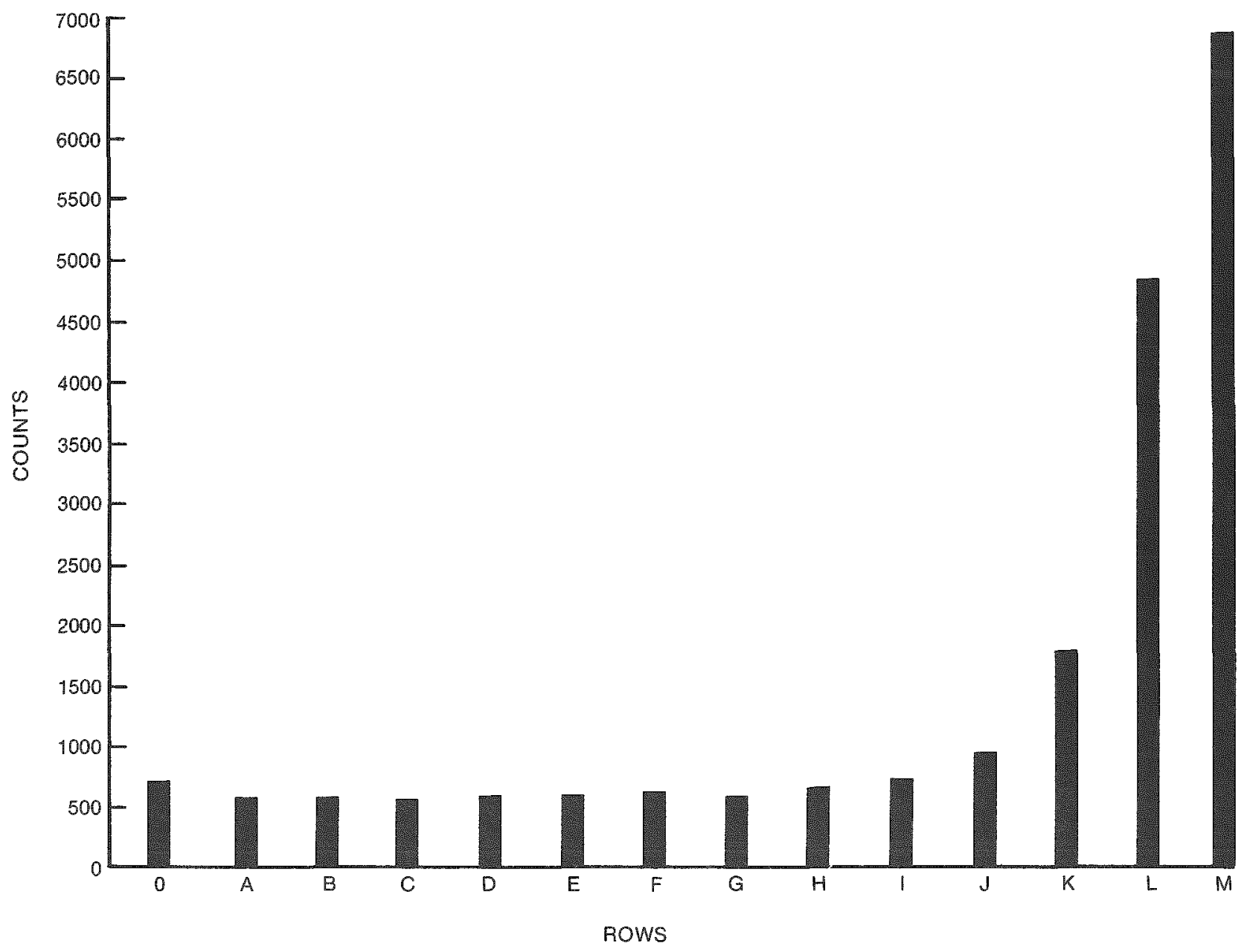

FIGURE 21. Experimental SAT. Source-simulated Holdup

Boron Scan. Column 2

feasibility of using the scanner to determine holdup for criticality control. To help determine scanner sensitivity, the background must be considered. The minimum amount of holdup detectable is influenced by the amount of background radiation. In these experiments, the background ranged from 5 to 10 neutrons par second. or 100 to 200 counts in the 20-second assay time." At a gor; confidence level. the count rate must be about 3 o higher than the backeround. A quick estimate of the amount of holdup detectable as a function of the background follows.

\footnotetext{
- Ihe background count rate as determmed by remoung the source from the area. and counting with the detector module. I he bakground count rate w medsured at rarous tmes during the expermentation process.
}

Assuming the holdup to be plutonium ovide. it would produce approximately 110 neutrons per gram per second." Therefore, the experimental calitomium252 source $\left(3.67 \times 10^{5}\right.$ neutrons/second $)$ simulated approsimately $3333 \mathrm{~g}$ of plutonium oxide holdup. The count rate was approximately 4800 counts when directly opposite the source. This count rate was statistically significant in a background of 200 counts.

Using the above assumptions, $2500 \mathrm{~g}$ of holdup would produce approximately $2.75 \times 10^{5}$ neutron, per second. Since the efficiency of the detectors is $0.07^{\prime} \%$ the holdup would create 193 count, per second at the detectors, or 3850 counts in 20 
seconds. Thus, TEST should detect $2500 \mathrm{~g}$ of holdup at these background rates.

A 200 -g mass of holdup would produce $2.2 \times 10^{4}$ neutrons per second. The detectors would then count 15 neutrons per second, or 308 neutrons in 20 seconds. Two hundred grams would be near the minimum holdup detectable with this background situation. Note that this is an idealized calculation. It does not take into account varying backgrounds, various holdup compositions, or any presence of water (hydrogen) in the holdup material. These factors would affect the minimum holdup detectable; thus. the above estimated minimum gram value would probably be higher for real measurements.

\section{PRODUCTION APPLICATION}

This section outlines a proposed TEST method for shielding verification of production SATs. The procedure begins with the SAT quality assurance (QA) then covers the shielding verification scans. A boron scan would be performed on each tank prior to installation in the process area for QA. The data from the scan would be compared to the shielding standard data. If the two sets of data were not statistically equivalent (as described in the Data Analysis section or Appendix D), the tank would fail the QA shiclding inspection.

Once the tank is installed in the process area but before it becomes contaminated, both holdup and boron scans would be performed. These scans would determine the "signature" of the tank: all following tank scans will be compared to the signature data. Boron sean data would be normalized using the holdup scan data, so shielding verification is independent of the holdup measurements. The normalized boron scan data would then be source decay corrected and compared to the signature data. If the data sets were statistically different, the tank would fail the shielding verification: otherwise, the tank would pass.

\section{FUTURE WORK}

For production, a reliable method is needed for taking background measurements. During the TEST
SAT experiments, the background was fairly constant, so a continuous background reading was not necessary. However, this condition will not hold true in the process areas where the SATs will be installed. In these areas, a background correction. ideally for each ROI. is necessary for comparisons of the tank from one scan to the next.

Currently, three methods are being analyzed to correct the individual counts for background. The first and preferred method is to design a "camera" to hold the source. The advantage of the camera would be its capability to "turn off" the source. At each ROI, two data sets would be collected: one with and one without the source. Thus, each data set may be background corrected.

The second method would add background detectors to the detector module. Although shielded from the source, background detectors will show the same background revealed by the main detectors.

A third method is being considered for later phases of the TEST. It would use a neutron generator instead of the californium-252 source. The generator can be turned on and off, so each ROI may be background corrected.

Another requisite for future work is the development of TEST standards, including shielding and holdup standards for calibration of the TEST scanner. These standards should be full diameter, though not necessarily full height. mockups of the SAT, traceable to a national standard. This task is being coordinated with the Rocky Flats Standards Laboratory.

\section{CONCLUSIONS}

These experiments show that TEST could be used for shielding verification. The outer ring of Rad-Stop missing over the entire height of the tank was detectable in a row or column. When approximately half of the innermost Rad-Stop ring was missing, the TEST determined that shielding was absent after summing the counts from one quadrant of the tank. The addition of the Rad-Stop piece was discernable in a row summed over almost half the tank. Twentyfive percent of the polyethylene missing was 
experimentally apparent in a tank quadrant using the collimated detector mode and in a row using the fast detector mode.

These experiments also indicate that the scanner may have a use for criticality control of holdup. However, further experiments should be performed to quantify TEST results.

Results of the scanner geometry experiments and resolution studies indicate that scanning with the source module positioned inside the center void of a SAT could increase the scanner's sensitivity while possibly decreasing the assay time. For these reasons. it is recommended that SATs be scanned in this manner. Of the three detector modes, the collimated detector mode is recommended because it provides sufficient sensitivity for the required inspection criteria.

\section{REFERENCE}

1. M. E. Anderson et al, MLM-3009. Monsanto Research, Mound Laboratory, Miamisburg, $\mathrm{OH}$, November 1982. 
RFP-4165 
APPENDIX A.

Rad-Stop Specifications

Rad-Stop is produced by Bisco Products. Inc.. Park Ridge. Illinois. The Rad-Stop was provided in rolls $1 / 8 \mathrm{in}$. thick and $2 \mathrm{ft}$ wide. It contains $60 \mathrm{mg} / \mathrm{cm}^{2}$ of boron.

Composition (wt \%)

Silicon 20.6

Oxygen 16.5

Hydrogen 2.6

Carbon 22.4

Boron 38.0 


\section{APPENDIX B.}

\section{TEST Equipment}

1. TEST Automated Scanner:

170 -in.-dia TEST track ring

1 electrical distributor

2 travel carts

2 hoist carts

2 hoist motor assemblies

2 cross-drive assemblies

2 counter weights

1 source module assembly

1 detector module assembly

1 slectronics cabinet (motor control system)

2. Neutron Counting Electronics:

1 Stantron instrument cabinet

1 Elgar $60006 \mathrm{~B}$ AC line regulator

1 Canberra 5005 system power

1 Ortec 456 high-voltage power supply

2 Ortec 142PC pre-amplifiers

1 Ortec 114 pre-amplifier power supply

2 Ortec 485 amplifiers

2 Ortec 550 single-channel analyzers

2 Ortec 772 counters

1 Ortec 773 timer

1 Ortec 779 communications interface

1 Ortec 401B/402D NIM bin

Cables and connectors

3. Californium-252 neutron source. Savannah River configuration. 5- $\mu \mathrm{g} .1 .2 \times 10^{7} \mathrm{n} / \mathrm{sec}$, March 22.1984.

4. Six banked helium-3 detectors. $6 \times 1 \mathrm{in}$. filled to $4 \mathrm{~atm}$.

5. Computer System:

SMS MDX-11 Computer (PDP $11 / 23+$ clone)

RSX 11 M-Plus operating system, version 2.1 BL15.8-in. RLO2 compatible floppy drive 36-Mb Winchester drive.

Envision 220 color graphics terminal

Envision 430 color printer/plotter

6. TEST Boron and holdup programs primarily RSX FORTRAN-77. 


\section{APPENDIX C.}

\section{Sample SATERR Program Output}

File erested hy Orosr Inout data taveri from pile collsortins created $26-0.5-86$
AUE
STLEV

0

2


$32.201977 .3 \quad 1649.0 \quad 2129.3$

$293.2 \quad 1645.0 \quad 1670.7 \quad 1714.3$

$\begin{array}{lll} & \end{array}$

$20.1 \quad 1009.71004 .71938 .3 \quad 1972.7$

$280.8 \quad 1673.0 \quad 2268.0 \quad 1-82.7 \quad 1675.0$

385.41755 .01310 .31850 .7

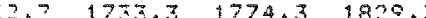

源

$437.1 \quad 1753.7 \quad 1793.0 \quad 2445.3$

$405.0 \quad 2355.3 \quad 1344,7 \quad 1755.0$

2411.01983 .02700

$\begin{array}{llll}412.9 & 3099.7 & 2520.7 & 340^{\circ} .7 \\ 402.4 & 3524.3 & 3988.7 & 4683.7\end{array}$

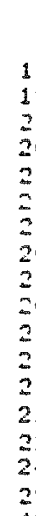

6

$\begin{array}{ll}1994.3 & 1974.3 \\ 1934.3 & 1953.0 \\ 2050.7 & 1990.7\end{array}$

$\begin{array}{ll}2050.7 & 1990.7 \\ 2002.7 & 1992.3\end{array}$

$2156.2 \quad 2073.3$

$\begin{array}{ll}2130.7 & 2000.7 \\ 2192.3 & 3095.0\end{array}$

$\begin{array}{ll}2174.7 & 2605.0 \\ 2147.7 & 2171.3\end{array}$

$2134.3 \quad 2112.0$

$2199.3 \quad 2159.3$

$2221.7 \quad 2173.7$

2305.32834 .3

$\begin{array}{ll}2375.3 & 2960.0 \\ 2497.3 & 2514.3\end{array}$

$2983.7 \quad 3744.3$

$\begin{array}{cccccc}7 & 8 & 9 & 10 & 11 & 12 \\ 1830.3 & 1829.7 & 1727.3 & 1720.3 & 1725.7 & 1705.0 \\ 1870.3 & 1783.3 & 1741.7 & 1701.3 & 1716.3 & 1706.3 \\ 1903.0 & 1811.0 & 1779.7 & 2201.7 & 1697.0 & 2255.7 \\ 1983.3 & 1888.0 & 1834.0 & 2151.3 & 1703.7 & 1709.7 \\ 1996.0 & 2396.3 & 1326.7 & 1823.0 & 1710.0 & 1729.0 \\ 2002.7 & 1945.7 & 2336.3 & 1884.0 & 1771.3 & 1778.0 \\ 1995.7 & 2445.0 & 1876.0 & 2153.7 & 1754.3 & 1769.0 \\ 2012.0 & 2432.7 & 2408.7 & 1822.0 & 1727.0 & 1741.7 \\ 2052.0 & 1955.3 & 2336.7 & 2309.7 & 1772.0 & 1740.7 \\ 2042.0 & 2505.0 & 1971.0 & 1887.3 & 1770.7 & 1754.0 \\ 2132.0 & 1989.7 & 2038.7 & 1944.0 & 1863.3 & 1789.0 \\ 2150.0 & 2614.7 & 2019.7 & 1929.7 & 1884.3 & 1868.0 \\ 2267.7 & 0.0 & 0.0 & 0.0 & 1856.7 & 1833.7 \\ 0.0 & 0.0 & 0.0 & 0.0 & 1846.7 & 1859.7 \\ 0.0 & 0.0 & 0.0 & 0.0 & 1848.7 & 1914.0 \\ 0.0 & 0.0 & 0.0 & 0.0 & 0.0 & 2051.7 \\ 0.0 & 0.0 & 0.0 & 0.0 & 0.0 & 2580.0 \\ 0.0 & 0.0 & 0.0 & 0.0 & 0.0 & 3770.0\end{array}$

$3 v e$
sta

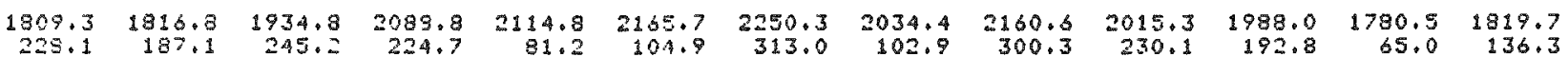

\begin{tabular}{|c|c|c|c|c|c|c|c|c|c|c|c|c|c|}
\hline & 13 & 14 & 15 & 16 & 17 & 18 & 19 & 20 & 21 & 22 & 23 & 24 & 25 \\
\hline & 1773.0 & 320 & 02.0 & 1 & 2 & 20 & 20 & 188 & 1815 & 16 & 3 & 21 & 1520 \\
\hline & & & & 350.3 & 233 & & 205 & 260 & & 175 & & 15 & \\
\hline & 172 & 306.9 & 1534.3 & 1920.0 & 2781.3 & 2030.0 & 2000.0 & 2622.0 & 2437.0 & 2278.3 & 1660.3 & 2125.0 & 2126,3 \\
\hline & & 37 & $8: 5$ & $1 \nexists 1$ & & & & & 31. & & & & \\
\hline & 178 & 30 & 1890 & & 270 & 208 & & 2000.7 & & & & 23 & \\
\hline & 1833.7 & 1780,0 & 1849.3 & 1758.0 & 2049.0 & $2155+3$ & 2103.3 & 2093.0 & $189 \div .3$ & 17 & .0 & 1634.0 & .0 \\
\hline & 2270.0 & 2325.7 & $\because \because 7$ & $=004.0$ & & & & & & & & & .3 \\
\hline & 205 & 80 & 37 & 202 & & & & & & & & & \\
\hline & 212 & 178 & $1858 .=$ & 2040.7 & 208 & $21+6.3$ & 2104.7 & 2019.0 & 256 & 243 & 230 & .3 & 8.3 \\
\hline & 178 & 257 & 180 & & & & & & & & & & \\
\hline & 180 & 185 & 12 & $1 \geqslant 8$ & & & & & & & & & \\
\hline & $13=$ & 176 & 200 & & & 22 & & & 2520.3 & 2585 & 2 & & \\
\hline & 193 & 245 & 35 & 271 & 29 & & & 205.7 & 0.0 & & 0.0 & & \\
\hline & $12 \mathrm{~s}$ & 13 & 25 & & & & & & & & & & \\
\hline & 240 & $\exists$ & $1=0$ & $28:$ & 23 & 31 & & 6 & 0 & 0 & 0 & 1778.3 & \\
\hline & & & & & & & & & & & & & \\
\hline & 333 & 41 & 35 & 276 & & & & & & & & & \\
\hline & 1720.7 & $315 .^{-2}$ & 5133.3 & 4053.0 & 4108.0 & 4213.0 & 4310.0 & 0.0 & 0.0 & 0.0 & 0.0 & 0.0 & 3859.3 \\
\hline & & & & & & & & & & & & & \\
\hline & & & & & & & & & & & & & \\
\hline
\end{tabular}

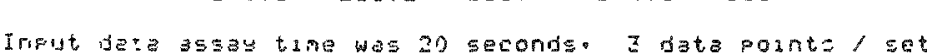

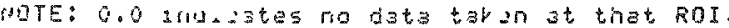

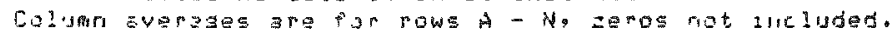




\section{APPENDIX D}

\section{Statistical Data Analysis}

Three data points were acquired at each region of interest (ROI). Counts from the three data points comprised a data set. The uncertainty on the individual data point was computed by:

$$
\begin{aligned}
\delta v_{i}= & \sqrt{v_{i}} \\
& \text { where } v_{i}=\text { counts for data point } i, i=1-3
\end{aligned}
$$

Data from each set were averaged. Counts recorded and graphed (unless otherwise noted) were averages of the data set. The uncertainty of the data set averages was calculated using:

$$
\begin{aligned}
\delta \bar{v} & =1 / 3 \sqrt{\Sigma \delta v_{i}^{2}} \\
& =1 / 3 \sqrt{\sum{\sqrt{v_{i}}}^{2}} \\
& =1 / 3 \sqrt{\sum v_{i}}
\end{aligned}
$$

When determining whether TEST could distinguish between various shielding configurations, comparisons were made on the sums of the data set averages, i.e.,

$$
\mathrm{N}=\delta \bar{v}_{1}+\delta \bar{v}_{2}+\delta \bar{v}_{n}
$$

The uncertainty on that sum was calculated as:

$$
\delta \mathrm{N}=\sqrt{\Sigma \delta \mathrm{v}_{\mathrm{i}}^{2}}
$$

The uncertainty terms computed above are at $1 \sigma(66 \%$ confidence level). For two numbers to be considered the same or not considered "statistically different," a 2- $\sigma$ uncertainty was used. The 2- $\sigma$ level was chosen to minimize the Type 2 error. (In this case, the error of stating the shielding was present when it was not.) To calculate the 2-o uncertainty, simply multiply the computed uncertainty by 2. c.g., $\delta \mathrm{N}$ $(2 \sigma)=2 * \delta \mathrm{N}$. For two numbers to be considered different at a $99 \%$ confidence level. a $3-\sigma$ uncertainty was used $(3 * \delta \mathrm{N})$. Two numbers, $\mathrm{nl} \pm \mathrm{ul}$ and $\mathrm{n} 2 \pm \mathrm{u} 2(\mathrm{ul}$ and $\mathrm{u} 2$ are the computed uncertainty). were considered the same if abs $(n 2-n 1)<2 * \sqrt{(u 1)^{2}+(u 2)^{2}}$. The numbers were statistically different at a $99 \%$ confidence level if abs $\left(n_{2} 2-n 1\right)>3 * \sqrt{(u 1)^{2}+\left(u_{2}\right)^{2}}$. 